\title{
Primary bone microanatomy records developmental aspects of life history in catarrhine
}

\section{primates}

\author{
Shannon C. McFarlin ${ }^{\mathrm{a}}$, Carl J. Terranova ${ }^{\mathrm{b}}$, Adrienne L. Zihlman ${ }^{\mathrm{c}}$, Timothy G. Bromage ${ }^{\mathrm{d}}$
}

${ }^{a}$ Center for the Advanced Study of Human Paleobiology, Department of Anthropology, The George Washington University, $80022^{\text {nd }}$ Street N.W., Washington, D.C. 20052, USA, mcfarlin@gwu.edu; ${ }^{b}$ Dauphine Street, New Orleans, LA 70117, USA, cterrano@tulane.edu; ${ }^{\mathrm{c}}$ Department of Anthropology, University of California Santa Cruz, 1156 High Street, Santa Cruz, CA 95064, USA, azihlman@ucsc.edu; dDepartment of Biomaterials and Biomimetics, New York University College of Dentistry, 345 East 24th Street, New York, NY 10010, USA, Tim.Bromage@nyu.edu

\section{Shannon C. McFarlin (CORRESPONDING AUTHOR)}

Department of Anthropology \& Center for the Advanced Study of Human Paleobiology

The George Washington University

Science and Engineering Hall

$80022^{\text {nd }}$ Street NW, Ste 6000

Washington, D.C. 20052 U.S.A.

Phone: (202) 997-6645, Fax: (202) 994-6097

Email: mcfarlin@gwu.edu

RUNNING TITLE: Primary bone microstructure and life history 
KEYWORDS: Bone histology, Life history, Growth and development, Old World monkeys, Apes

\author{
ABBREVIATIONS: \\ CPL Circularly polarized light microscopy \\ DECID Biological age class defined by alveolar emergence of one or more deciduous \\ teeth \\ ECC Compacted coarse cancellous bone; tissue type of endosteal origin \\ ELAM Lamellar bone; tissue type of endosteal origin \\ EPIPH Biological age class defined on the basis of long bone epiphyseal union \\ EPF Parallel-fibered bone; tissue type of endosteal origin \\ EPF-LAM Transitional parallel-fibered to lamellar bone; tissue type of endosteal origin \\ FLC Fibro-lamellar complex; tissue type of periosteal origin \\ FLC-LZPO Transitional fibro-lamellar complex to lamellar-zonal bone; tissue type of \\ periosteal origin \\ FLC+LZPO FLC and FLC-LZPO tissue types grouped for statistical analysis \\ HAV Haversion bone (i.e., secondary osteonal bone) \\ LAG Line of arrested growth \\ LAM Lamellar bone; tissue type of periosteal origin \\ LM Brightfield microscopy \\ M1 Biological age class defined by alveolar emergence of one or more first \\ permanent molars
}


M2 Biological age class defined by alveolar emergence of one or more second permanent molars

M3 Biological age class defined by alveolar emergence of one or more third permanent molars

PF Parallel-fibered bone; tissue type of periosteal origin

PF-LAM Transitional parallel-fibered to lamellar bone; tissue type of endosteal origin SF $\quad$ Sharpey fiber bone 
ABSTRACT: A central challenge in human origins research is to understand how evolution has shaped modern human life history. As fossilized remains of our ancestors provide the only direct evidence for life history evolution, efforts to reconstruct life history in paleontological contexts have focused on hard tissues, particularly on dental development. However, among investigators of other vertebrate groups, there is a long tradition of examining primary bone microstructure to decipher growth rates and maturational timing, based on an empirical relationship between the microanatomy of primary bone and the rate at which it is deposited. We examined ontogenetic variation in primary bone microstructure at the midshaft femur of Chlorocebus aethiops, Hylobates lar, and Pan troglodytes to test whether tissue type proportions vary in accordance with predictions based on body mass growth patterns described previously. In all taxa, younger age classes were characterized by significantly higher percent areas of fibro-lamellar and/or parallel-fibered tissues, while older age classes showed significantly higher proportions of lamellar bone. In prior experimental studies, fibro-lamellar and parallel-fibered tissue types have been associated with faster depositional rates than lamellar bone. Principal components analysis revealed differences among taxa in the timing of this transition, and in the particular tissue types observed among individuals of similar dental emergence status. Among M1 and M2 age classes, higher proportions of parallel-fibered and fibro-lamellar tissues were observed in those taxa characterized by reportedly faster body mass growth rates. Further, persistence of fibro-lamellar tissue throughout DECID, M1 and M2 age classes in chimpanzees contrasts with the pattern reported previously for modern humans. Despite the necessary limitations of our cross-sectional study design and the secondary remodeling of bone in primates, large areas of primary bone remain intact and represent a valuable and independent source of information about the evolution of growth and development in the fossil record. 


\section{Introduction}

The study of life history is concerned with those events and developmental processes that occur during the life cycle, and which determine the manner in which organisms allocate energy towards growth, reproduction and maintenance to optimize reproductive effort over their life span (Smith, 1992; Leigh and Blomquist, 2007). Ontogeny has figured prominently in the study

of primate life histories, as offspring growth trajectories are governed by energetic trade-offs that determine changes in allocation towards the maturation of different body systems throughout life. Prior work has shown that different anatomical organs/systems (e.g., brain, body, dentition, and reproductive) may be developmentally dissociated from one another, and their growth rates and timing subject to independent selection (Watts, 1990; Leigh and Park, 1998; Bolter and Zihlman, 2003; Pereira and Leigh, 2003; Godfrey et al., 2004; Leigh and Bernstein, 2006; Dirks and Bowman, 2007). These diverse 'modes' of development underlie important differences in primate life history strategies (Pereira and Leigh, 2003). Shifts in the rate and timing of different body systems, namely dental versus skeletal growth, also characterize fossil hominins, suggesting that modularity may underlie life history evolution in the human lineage (Smith, 1993; Pereira and Leigh, 2003; Dean and Smith, 2009).

A major focus of our efforts to understand how evolution has shaped primate life history strategies has been on hard tissue features observable in fossils. Among investigators of other vertebrate groups, including mammals, there is a long tradition of examining the microscopic organization of primary bone tissues (i.e., those deposited during growth, as opposed to secondary remodeling) in both modern and fossil samples as a means of revealing life history information, including growth rates, maturational timing, and longevity (Enlow, 1966; Castanet et al., 1993; Ricqlès, 1993; Klevezal, 1996; Padian et al., 2001; Chinsamy-Turan, 2005; 
Erickson, 2005; Castanet, 2006; Köhler and Moyà-Solà, 2009; Padian, 2013). The microscopic organization of bone records a history of its growth and development, and thus represents a potentially rich source of information about the various ontogenetic, environmental, local and phylogenetic factors that influence its formation and maintenance during life (Enlow, 1963; Enlow, 1966; Ricqlès, 1993; Martin et al., 1998; Currey, 2002; Legendre et al., 2013). Yet, its significance for revealing developmental aspects of life history in primates has been largely unexplored, with a few notable exceptions. The current study begins to address this shortcoming. Identifying shifts in dental development has been critical to our understanding of human life history evolution from evidence available in the fossil record (e.g., Bromage and Dean, 1985; Smith, 1992; Dean, 2010; Schwartz, 2012). However, a foundation based on the incorporation of studies of tooth and bone microanatomy in the same individuals would allow us to more fully address questions concerning developmental modularity and the evolution of other unique human life history traits, such as our slow somatic growth during childhood (Bogin and Smith, 1997; Leigh, 2001; Bromage et al., 2009b; Dean and Smith, 2009).

\section{Bone microanatomical diversity}

The cells, vascular canals, and collagen fiber matrix of bone combine to produce stereotypical patterns of microanatomical organization, often referred to as bone 'tissue types'. While bone microanatomy varies along a continuum, investigators have historically used typological classifications to characterize diversity and facilitate comparisons among groups (e.g., Quekett, 1855; Foote, 1916; Amprino and Godina, 1947; Enlow and Brown, 1956; Smith, 1961; Enlow, 1963; Pritchard, 1972; Ricqlès, 1975; Francillon-Vieillot et al., 1990). Figure 1 depicts different tissue types that have been described previously, or are observed here, to occur 
in primate bone. These tissue types are recognized on the basis of multiple criteria, such as developmental origin, collagen fiber organization, and vascularization (Enlow, 1963; Ricqlès, 1969, 1975, 1977; Francillon-Vieillot et al., 1990; Ricqlès et al., 1991; Enlow and Hans, 1996). (See Supplementary Online Material [SOM] for a more comprehensive description of tissue type diversity as it pertains to the current study.) Bone tissue type distributions vary considerably among vertebrate taxa, individuals of different ages, and within single skeletons (Quekett, 1855; Foote, 1916; Demeter and Mátyás, 1928; Amprino and Godina, 1947; Enlow and Brown, 1956, 1957, 1958; Singh et al., 1974). This diversity can be largely understood as a reflection of ontogenetic, local (e.g., biomechanical), environmental (e.g., nutritional) and phylogenetic factors (Enlow, 1963; Ricqlès, 1993; Martin et al., 1998; Castanet et al., 2001; Currey, 2002; Pearson and Lieberman, 2004; Ricqlès, 2007; Gosman, 2012; Maggiano, 2012).

\section{$\ll<$ FIGURE $1 \gg$}

As bones increase in linear and cross-sectional size during growth through endochondral and intramembranous ossification, their characteristic adult morphologies are achieved through a sequence of modeling changes at the microscopic level (termed 'growth remodeling' by Enlow, 1963; Frost, 1973). Modeling involves spatially and temporally coordinated patterns of resorption and formation on different endosteal, cancellous and periosteal bone surfaces; it is distinct from the turnover process of bone remodeling, which entails the coupled activity of osteoblasts and osteoblasts at single bone sites (Enlow, 1963; Frost, 1973; Parfitt, 1983; Jee et al., 2007). Local dynamics of bone modeling during growth are subject to the interacting influence of genetic, hormonal and environmental (e.g., nutrition) factors, and requirements to produce changes in regional and whole bone structural properties that are mechanically appropriate (Enlow, 1963, 1966, 1976; Parfitt, 1983; Frost, 1990a, b; Martin et al., 1998; Currey, 
2002; Pearson and Lieberman, 2004; Jee et al., 2007; Gosman, 2012; Maggiano, 2012).

Modeling results in the sequential relocation of bone tissue areas in space as growth proceeds, serving to maintain or to achieve local adjustments in bone shape with increases in overall bone size. Cortical drift is one such modeling process involved, for example, in the development of long bone diaphyseal curvature; through coordinated patterns of bone deposition and resorption on complementary endosteal and periosteal surfaces, it results in the directional movement or 'drift' of the bone cortex in morphological space. Modeling may entail differential rates of osteogenesis across bone regions, and local destruction of tissues deposited during earlier growth stages; together with secondary remodeling, it determines the regional distribution of tissue types within cross-sections. As a result, bone has a highly stratified and heterogeneous appearance in cross-section, where each stratum characterizes a stage of deposition that may vary in its microanatomical organization or growth direction from adjacent strata (Enlow, 1963). Histological 'signatures' of modeling (e.g., cement lines indicating reversals in growth direction) were clarified by Enlow (Enlow, 1962, 1963, 1976, 1982), and their consistency with features associated with formative and resorptive activity on bone surfaces observed in scanning electron microscopy have been demonstrated (Saunders, 1985), thus making it possible to reconstruct the sequential changes that occurred throughout the growth history of a given cross-section of bone for the purposes of revealing information about developmental aspects of life history.

\section{Significance of primary bone microanatomy for life history research}

The heterogeneous microscopic appearance of bone in cross-section preserves a record of growth rate variability during its development, which, when interpreted within the context of local bone modeling and remodeling circumstances, represents a unique source of information 
about individual developmental history that cannot be gleaned from macroscopic studies of the skeleton alone. Amprino (1947) was the first to propose a relationship between the microscopic organization of primary bone tissues, particularly tissues of periosteal origin, and the rates at which they are deposited. In a series of comparative studies, including examinations of human bone, he observed that primary bone tissue types show considerable variation during ontogeny within species; deposition of loosely organized woven bone characterizes periods of rapid growth, while a transition to more highly ordered lamellar bone characterizes periods of slow growth (Amprino and Godina, 1947). Further, he observed that animals characterized by different rates and patterns of somatic growth also differ substantially in the timing and succession of primary bone tissue types deposited in their limb skeletons throughout ontogeny. Amprino's hypothesis has since been confirmed in examinations of a wide range of vertebrates (e.g., Amprino and Godina, 1947; Enlow and Brown, 1956, 1957, 1958; Enlow, 1962; Ricqlès et al., 1991). Recent vital fluorochrome labeling studies have shown that nonvascular lamellar bone is characterized by the lowest rates of periosteal deposition, typically less than 0.3 micron/day in most vertebrates studied, including many mammals (see Ricqlès et al., 1991 and references therein). Mammalian lamellar bone growth rates vary at this slow end of the continuum, depending upon surface topography, osteoblast recruitment and life history (Bromage et al., 2009b, 2011). While there is some overlap, non-vascular parallel-fibered bone may be deposited at slightly faster rates, reportedly $0.10-0.5$ microns/day, while depositional rates of woven bone are most commonly between 0.3 - 5.0 microns/day (Ricqlès et al., 1991; Castanet et al., 2004). Bone tissues of endosteal and secondary origin appear to be deposited at faster rates than periosteal tissues having the same collagen fiber matrix and vascular organization (Yen and Shaw, 1977; Yen et al., 1978; Buffrénil and Pascal, 1984; Ricqlès et al., 
1991; Balena et al., 1992; Margerie et al., 2002; Parfitt, 2002). Further, the blood supply of primary bone has also been shown to vary in accordance with depositional rate, as more highly vascularized tissues are associated with faster deposition than less vascularized tissues having a similar collagen fiber organization (but see Starck and Chinsamy, 2002). In a series of systematic studies of extant avians by Castanet and colleagues (Castanet et al., 1996, 2000; Margerie et al., 2002, 2004), vascular fibro-lamellar tissue types were the most rapidly deposited primary bone tissues, characterized by rates of osteogenesis that were typically greater than 5-10 $\mu \mathrm{m} /$ day. These findings are in agreement with studies of mammalian bone, including primates (NewellMorris and Sirianni, 1982; Buffrénil and Pascal, 1984; Ricqlès et al., 1991; Castanet et al., 2004).

Prior studies of primary bone microanatomy in humans and other primates

Primates have been included in a number of broadly comparative studies of vertebrate bone histology to date (Quekett, 1855; Foote, 1916; Demeter and Mátyás, 1928; Amprino and Godina, 1947; Enlow and Brown, 1958; Jowsey, 1966, 1968; Singh et al., 1974; Brits et al., 2014), which demonstrated considerable ontogenetic and taxonomic variability in both the microscopic organization of primary bone tissues and the extent and distribution of secondary remodeling. While these studies have led to an appreciation of general trends and the range of variation observed among species, they have tended to utilize bone samples collected opportunistically from a variety of anatomical locations, animals frequently of unknown sex and/or age, and taxa represented by only a handful of specimens (see Enlow, 1966; Ricqlès 1993). More recent systematic examinations of long bone microanatomy in primates have tended to focus on secondary remodeling (e.g., Schaffler and Burr, 1984; Burr, 1992; Paine and Godfrey, 1997; Mulhern and Ubelaker, 2003; Havill, 2004; Skedros et al., 2011; Streeter, 2012) 
and the utility of bone histology for distinguishing human from nonhuman bone or in archaeological contexts (Hillier and Bell, 2007; Maggiano et al., 2011; Mulhern and Ubelaker, 2012). The value of primary bone microstructure for addressing questions of life history significance has been rarely explored in primates (Enlow, 1966), with a few notable exceptions.

Two investigations have employed fluorescent vital labeling techniques to investigate bone growth in nonhuman primates, and demonstrated significant changes in the microanatomical structure of periosteal bone deposits coincident with changes in somatic and bone growth rates during early ontogeny. Newell-Morris and Sirianni (1982) observed variation in the collagen fiber matrix and a decline in primary osteon number at the midshaft humerus of pig-tailed macaques (Macaca nemestrina), which was associated with a decline in periosteal bone depositional rates during the late fetal and early neonatal period. They reported mean periosteal depositional rates for vascularized woven bone (equivalent to fibrolamellar complex here) at 9.8 microns/day during the fetal period, vascular parallel-fibered bone at approximately 4 microns/day in 11-week neonates, and vascular lamellar bone at approximately 1.5 microns/day in 60-week animals. In a study of captive gray mouse lemurs (Microcebus murinus), Castanet and colleagues (2004) reported a dramatic decrease in bone depositional rates at the midshaft tibia as animals approached the end of their first growing season in other body measurements; this slow-down in osteogenesis was associated histologically with an abrupt transition from deposition of parallel fibered bone containing numerous vascular canals (at rates of 3-8 microns/day) to avascular parallel-fibered bone (rates as low as 0.1 micron/day). Other studies of existing skeletal samples (not subject to vital labeling) have also demonstrated correspondence between primary bone microanatomy and somatic growth patterns in primates, including humans (Pfeiffer, 2006; Warshaw, 2008; Goldman et al., 2009; Cambra-Moo et al., 
2014).

These studies have demonstrated the potential of primary bone microanatomy for revealing important information about developmental aspects of life history in primates, including variability in growth rates over the course of ontogeny. However, we still lack basic information concerning quantitative variability in primary bone microanatomy across many nonhuman primate species, throughout postnatal development and adulthood, and across different skeletal sites. The current study begins to address these shortcomings. If the utility of primary bone microanatomy for interpreting variation in somatic growth patterns can be demonstrated in a sample of Old World anthropoid primates, including apes, this can contribute towards an important comparative framework and independent line of inquiry into the evolution of human life history from the fossil record.

\section{Objectives of the current study}

We examine ontogenetic variability in primary bone microanatomy at the midshaft femur in a comparative sample of wild-collected Old World anthropoid primates, and consider its significance for revealing differences in somatic growth patterns. While the invasive nature of histologic sampling protocols limited the number and taxonomic scope of specimens available for study, three taxa were examined here: Chlorocebus aethiops (formerly Cercopithecus aethiops; vervet monkeys), Hylobates lar (white-handed gibbons) and Pan troglodytes (common chimpanzees). (Table 1). These taxa were selected because they allow for comparisons to be made between primary tissue type distributions during ontogeny and body mass growth patterns described previously by other investigators (e.g., Leigh and Shea, 1995; Hamada et al., 1996; Leigh, 1996; Turner et al., 1997; Hamada and Udono, 2002; Bolter and Zihlman, 2003). 


\section{$<<$ TABLE $1 \gg>$}

We address the following question in this study: Do primary bone tissue type proportions vary in accordance with predictions based on body mass growth patterns? Body mass loads have an important influence on growth-related increases in the cross-sectional dimensions of long bone diaphyses (Ruff et al., 1994; Moro et al., 1996; van der Meulen et al., 1996). Due to the paucity of available baseline data on primary bone microanatomical variation in primates, the following predictions of this study are necessarily general in nature:

A) Intraspecific patterns. Primary bone tissue type proportions are expected to vary with age within taxa. During times of rapid body mass growth (i.e., during early ontogeny), individuals are expected to show higher proportions of bone tissues types associated with faster depositional rates (e.g., fibro-lamellar tissue, having a woven-fibered matrix component and greater vascularity). Highly-ordered, less vascular (e.g. lamellar) bone tissues will occur in higher proportions as body mass growth slows during late ontogeny. In those taxa (C. aethiops, P. troglodytes) characterized by sexual dimorphism in growth or the presence of a subadult growth spurt, tissue type proportions are expected to vary accordingly; fibro-lamellar bone tissues should occur in higher proportions in males and during the subadult growth spurt.

B) Interspecific variability. Among individuals of similar dental emergence status, those species characterized by faster absolute rates of body mass growth (P. troglodytes) are expected to show higher proportions of tissue types associated with fast depositional rates compared to those taxa characterized by slower rates of body mass growth (C. aethiops and H. lar).

We focus here on the quantitative analysis of periosteal bone tissue types, which are understood to have relevance for interpreting bone growth rate variability during ontogeny. However, endosteal tissue types are also quantified, and other features of primary bone histology 
qualitatively described, to provide a baseline understanding of primary bone features having possible relevance for interpreting local bone growth circumstances and life history.

\section{Materials and methods}

Sample materials.

Relying on existing collections of wild primate skeletal remains, we examined ontogenetic series of Chlorocebus aethiops from northwest Uganda [vervet monkey; Sherwood L. Washburn Collection, University of California at Santa Cruz (SLW-UCSC), $n=32$ ]; Hylobates lar from Chiengmai, Thailand [white-handed gibbon; Museum of Comparative Zoology, Harvard University (MCZ), n=14; Sherwood L. Washburn Collection, University of California at Santa Cruz (SLW-UCSC), n=14]; and Pan troglodytes from Cameroon, Gabon and western D.R. Congo [common chimpanzee; Museum für Naturkunde der Humboldt Universität in Berlin (MfN), $n=12]$. (Table 2).

$<<$ TABLE $2>>>$

To reduce potential variation in life history among animals living under different environmental conditions (e.g., Altmann and Alberts, 1987, 2005; Breuer et al., 2009; Hamada and Udono, 2002), every effort was made to comprise each species' sample of wild-collected individuals from restricted geographic localities. While this was possible for the C. aethiops and $H$. lar samples, there is more geographic variation in the P. troglodytes sample, as described more fully in McFarlin (2006). Further, since the goal of this study was to examine variability in bone microanatomy related to growth-related aspects of life history, only immature individuals and non-geriatric adults (as defined below) were included.

In the absence of chronological age information, we grouped individuals into five 
biological age classes based on dental alveolar emergence and long bone epiphyseal union. Individuals with one or more emerged deciduous teeth and lacking emergence of permanent molars were assigned to the infant ('DECID') age class. Individuals were assigned to three juvenile age classes ('M1', 'M2', and 'M3') based on alveolar emergence of one or more first, second or third permanent molars, respectively. Individuals continue skeletal development after full eruption of the dentition (Watts 1990; Bolter and Zihlman, 2003; observations of the current study). Thus, individuals were considered fully mature ('EPIPH' age class) only after complete fusion of all long bone epiphyses, although it is acknowledged that appreciable modeling changes at the periosteal and endosteal surface may continue into adulthood (Garn et al., 1972). Biological age classification and methods for assessing dental emergence and long bone epiphyseal union were modified from Bolter and Zihlman (2003). All individuals included in the study lacked obvious evidence of skeletal fracture, pathology, and osteoarthritis (Ortner, 2003; White et al., 2011). Older adults were also excluded on the basis of advanced occlusal wear of the first permanent molars, as described in McFarlin (2006).

\section{Sampling location.}

We report here on primary bone microanatomical development at the midshaft femur. A previous examination of the current sample demonstrated increased secondary intracortical remodeling and more pronounced lateral cortical drift at the midshaft humerus compared to the midshaft femur (McFarlin et al., 2008), hence our decision to focus on the latter skeletal site here. Further, other researchers (Lieberman et al., 2003; Warshaw, 2007) have demonstrated that proximal limb segments show reduced secondary intracortical remodeling compared to distal limb segments (but see Drapeau and Streeter, 2006), leaving more primary bone areas intact. 
Midshaft was chosen since sites located more proximally or distally along the diaphysis are subject to more destructive modeling processes, namely metaphyseal reduction, in which the periosteal cortex is largely resorptive (Enlow, 1962, 1963; plus our pilot observatons). To utilize adult and immature specimens lacking fused epiphyses, midshaft location was determined based on a measure of diaphyseal length, described in McFarlin (2006).

Sample preparation, image acquisition, processing and quantification.

One-centimeter tall cylinders of bone encompassing the entire diaphyseal midshaft were extracted from each element, cleaned of adhering soft tissue in 1\% Terg-A-Zyme (Alconox, N.Y.), dehydrated, and refluxed in a Soxhlet for one to two weeks (depending on block size) in a 50:50 solution of isopropanol : heptane for further dehydrating and defatting prior to embedding in polymethylmethacrylate. Embedded block surfaces were prepared and mounted on glass slides, and histological thin sections prepared following Goldman et al. (1999) with some modifications. Thin sections were ground to a final uniform thickness of $100 \pm 5 \mu \mathrm{m}$ at a surface topography of 1200 grit, and cover-slipped with ethylene glycol for optimum optical performance.

Same field-of-view images were acquired in brightfield (LM) and circularly-polarized light (CPL) microscopy, to visualize the organization of bone cells and vascular canals, and variation in birefringence understood to reflect the organization of the collagen fiber matrix of bone, respectively (Bromage et al., 2003). Imaging was performed using a Leica DMRX/E Universal microscope configured with an automated Marzhauser stage $(0.1 \mu \mathrm{m}$ accuracy in XY). Whole cross-section images were obtained using a JVC KY55BU/BE color CCD camera, integrated with a Syncroscopy Montage Explorer system (Synoptics Ltd., Cambridge, UK.). 
LM and CPL images were imported into Adobe Photoshop 6.0 (Adobe Systems Inc., San Jose, CA.), and superimposed for visualization and quantification of bone areas represented by different bone tissue types. First, non-bone areas (e.g., medullary canal, resorption spaces) were assigned to a background color so they could be deleted in later quantitative analyses. Second, bone areas comprised of different tissue types were manually traced and color-coded, thus creating a composite tissue type map. [This approach is similar to that employed recently for studies of human bone by Cambra-Moo et al. $(2012,2014)]$. Each tissue type map was then imported into Optimas 6.5 Image Analysis software (Media Cybernetics Inc., Silver Spring, MD) for quantitative analysis using a customized macro (described by Feik et al., 2000; Goldman et al., 2003), which calculated the number of pixels represented by each tissue type.

As a measure of whole cross-section size, cortical area $\left(\mathrm{CA}, \mathrm{mm}^{2}\right)$ was calculated in NIH Image 1.63, a public domain image analysis program available through the National Institutes of Health, using a macro ('MOMENTMACRO') made available online by Dr. Christopher Ruff. $<<$ FIG 2 TISSUE MAPS $\gg \gg$

\section{Classification of primary bone tissue types.}

Patterns of bone microscopic organization were classified into a number of tissue 'types', following the comprehensive scheme proposed by Ricqlès and colleagues (summarized in Francillon-Vieillot et al., 1990), with some modifications. Endosteal compacted coarse cancellous tissue, described by Enlow (1963), was also recognized in the current study. Furthermore, two transitional tissue types were recognized: (1) FLC-LZPO, a transitional tissue type between classically defined fibro-lamellar complex (FLC) and lamellar-zonal bone vascularized with primary osteons (LZPO); and (2) PF-LAM, a transitional tissue type between parallel-fibered (PF) and lamellar (LAM) bone. As FLC was rarely observed, the FLC and FLC- 
LZPO tissue types were grouped in most statistical analyses (FLC + LZPO).

Tissue types examined in the current study are shown in Figure 2, and were identified on the basis of several criteria reviewed above, including organization of the collagen fiber matrix of bone as imaged in CPL, and bone vascularity, osteocyte lacunar shape and distribution as observed in LM microscopy. These criteria have been employed in prior studies of primary bone microstructure in other primates (Castanet et al., 2004; Pfeiffer, 2006; Warshaw, 2008; Goldman et al., 2009). Specific criteria for distinguishing among different tissue types in the current study are provided in SOM (also see McFarlin, 2006; Warshaw, 2008).

\section{Statistical analysis.}

The area proportion of primary bone tissue types (TT) was calculated as a percentage of total cortical area from raw pixel dimensions according to the following equation:

$\% \mathrm{TT}=($ pixel dimensions of $\mathrm{TT} /$ cortical area pixel dimensions $) * 100$

Statistical analysis was restricted to whole cross-section proportions of primary bone tissue types, focusing particularly on tissues of periosteal origin. All analyses were performed using nonparametric statistics (Statistica 6.0, Statsoft, Inc.), given small samples within age classes.

Most analyses were restricted to intraspecific comparisons. Associations of $\%$ area of bone tissue types with age class and cortical area were examined using Spearman rank order correlation. Contrasts among group medians were made using Kruskal-Wallis and MannWhitney tests, with age class and sex as factors. Where Kruskal-Wallis tests revealed significant contrasts among age classes, post-hoc pair-wise Mann-Whitney tests were performed to identify significant contrasts. Probability values arising from post-hoc comparisons were corrected for repeated tests using the Bonferroni method, in which $p$ was divided by the number of total 
comparisons (Sokal and Rohlf, 1995). Finally, the influence of sex on the age-related succession of primary bone tissue types was difficult to evaluate within taxa, given small and unequal sample sizes for males and females particularly in the youngest age classes. Thus, statistical contrasts among sexes were restricted to a subsample comprised of M3 - EPIPH age classes. Categorized bivariate plots were also inspected for consistent differences between sexes in $\%$ area of tissue types in C. aethiops and H. lar.

Principal components analysis (PCA) was undertaken for data visualization purposes, and to summarize the variance contained within the entire dataset and detect broad interspecific patterns in proportions of primary bone tissue types at the midshaft femur. Active input variables for calculation of principal components included \% of total cortical area of END, and the $\%$ of primary periosteal cortex area of FLC + LZPO, PF, PF-LAM, and LAM. Age class and cortical area were included as supplemental variables in Statistica 6.0 (Statsoft, Inc.).

\section{Results}

Variability in \% area of tissue types was significantly correlated with age class and cortical area (CA) in all taxa examined (Table 3). The pattern of association of microstructural variables with age class and CA was the same, and these latter two variables were significantly correlated with one another (Spearman rank order correlation statistics: $C$. aethiops femur, $r=$ 0.8763, $p=0.0000 ; H$. lar femur, $r=0.8804, p=0.0000 ; P$. troglodytes femur, $r=0.9176, p=$ 0.0000). Associations among variables tended to be nonlinear, as can be appreciated in Figure 3 . $<<<$ TABLE 3 - SPEARMAN CORR $\gg>$ $<<<$ FIGURE 3-BIVARIATE PLOTS OF FLC-LZPO, LAM, END>>>

All three taxa were characterized by a statistically significant decrease in periosteal \% FLC + 
LZPO, \%PF, and \%PF-LAM, and increase in \%LAM, with increasing age and size at the midshaft femur. Among endosteal tissues, \%EPF and \%EPF-LAM showed a significant negative correlation with age class and CA in H. lar and P. troglodytes, but not C. aethiops. $\%$ ELAM and \%ECCC increased significantly with age class and CA at the midshaft femur of $C$. aethiops, while the opposite pattern was observed in H. lar. In P. troglodytes, variation in $\%$ ELAM and \%ECCC was not significant.

<<<TABLE 4 - STAT CONTRASTS AMONG AGE CLASSES, ALL TAXA »> <<<FIGURE 4 - AGE CLASS MEAN/MEDIAN PLOT $\gg>$ $<<<$ FIGURE 5 - TISSUE TYPE MAPS, ONTO SERIES $>>>$

These age trends are considered in further detail below by taxon, with a particular focus on tissue types of periosteal origin. Since statistically significant sex differences were not found for any age class in the taxa examined here, results are based on combined-sex samples. Tissue type maps from all individuals in the sample are provided in SOM Figures 2-4.

C. aethiops.

Combined fibro-lamellar tissue types (FLC and FLC-LZPO) comprised a large proportion of total cortical area compared to lamellar-zonal tissue types (PF, PF-LAM and LAM) in the DECID age class (Figs. 4 and 5). However, this pattern changed markedly in the M1 age class, where LAM tissue comprised a large majority of cortical area. In all older age classes, non-LAM primary periosteal tissues (except SF) typically comprised less than $5 \%$ of total cortical area. The total proportion of END tissues increased with age, though still comprised $<10 \%$ of total cortical area on average (SOM Table S-1).

Statistical analysis supported these trends. Significant variation was observed among age 
classes for most primary periosteal tissue types and endosteal bone at the midshaft femur, except PF (Table 4). Post-hoc comparisons revealed significant contrasts $(p \leq 0.05)$ between the DECID and/or M1 age class and older age classes in fibro-lamellar tissues and PF-LAM. $<<<$ FIGURE 6 - CAETHIOPS QUAL OBSERVATIONS $\gg>>$

Qualitative observations. Considerable variability in tissue type proportions and other features of primary bone microanatomy was observed within the DECID age class compared to older age classes, particularly in fibrolamellar (FLC, FLC-LZPO) and LAM tissue types (SOM Figs. S-2ae.) The two individuals (SLW 62 and 92) that showed the highest proportions of fibrolamellar tissue types were also characterized by smaller cortical areas and incompletely-emerged deciduous dentitions, compared to larger individuals with complete deciduous dentitions. However, inter-individual variability was also observed among individuals of similar dental emergence status and size (e.g., SLW 33 and SLW 27).

Qualitative assessment revealed variability in additional features of primary bone microanatomy, such as vascularity, which could not be appreciated in the quantitative analysis of bone tissue types alone. (compare Fig. 6A to 6B-C). Further, annuli and resting cement lines were observed in the primary periosteal femoral cortex in two individuals of the DECID age class and in all older individuals examined (Figs. 6B and C). These cement line structures, termed lines of arrested growth, lack the scalloped appearance of reversal cement lines; they instead form during temporary cessations or slow-downs in deposition. These growth marks varied in the severity of their expression among individuals, as revealed by their contrast in LM and birefringence under CPL. Variability was also observed in the number of growth marks present throughout the cortical thickness of single cross-sections, often being more numerous in 
individuals of older age classes.

H. lar.

Lamellar-zonal tissues comprised the greatest proportion of the primary periosteal cortex in the DECID age class, with PF-LAM tissue being the most abundant (Figs. 4 and 7). A similar pattern characterized the M1 age class. The most substantial change in tissue types was evident in the M2 age class, characterized by an increase in \% LAM, representing nearly half of total cortical area on average, and a decrease in proportions of other periosteal tissue types. This trend continued through the M3 and EPIPH age classes. END tissue was most abundant in the DECID age class, and showed a gradual decrease thereafter (SOM Table S-1b).

Statistical analyses revealed significant variation among age classes for most periosteal tissue types (except FLC) and endosteal bone (Table 4). Post-hoc contrasts in periosteal tissue types were only significant $(\mathrm{p} \leq 0.05)$ between the $\mathrm{M} 2$ and older age classes, supporting a more gradual age-related transition in primary tissue types compared to that observed in C. aethiops.

\section{<<<FIGURE 7 - HLAR QUAL OBSERVATIONS >>>}

Qualitative observations. In contrast to older age classes, endosteally-deposited bone (including ECC) was more commonly observed and distributed in inner and mid-cortical regions of the midshaft in the DECID age class (Fig. 7A and SOM Figs S-3a-e). The majority of the primary periosteal cortex in DECID individuals was comprised of poorly vascularized PF and / or LAM deposition. In contrast, fibro-lamellar tissue (FLC-LZPO), characterized by a predominantly longitudinal vascular canal orientation, was typically observed in the innermost periosteal cortex, often in or near regions undergoing secondary intracortical remodeling. 
Qualitative inspection revealed that LAM in the M1 and older age classes was either avascular or sparsely vascularized with primary osteons and simple primary vascular canals having a longitudinal orientation (Fig. 7B and C). Lines of arrested growth and/or annuli, more numerous in individuals of older age classes, were also common features of LAM cortex.

P. troglodytes.

Small sample sizes precluded statistical contrasts among age classes, but Spearman correlation analyses supported the age trends described here (Table 3). The majority of primary periosteal cortex was comprised of FLC-LZPO and PF-LAM in the DECID age class, whereas FLC-LZPO and LAM each comprised a high proportion of total cortical area in the single individual representing the M1 age class (Figs. 4 and 8). The M2 age class showed a similar pattern. A continued decrease in FLC-LZPO and a corresponding increase in LAM characterized the M3 and EPIPH age classes. Mean proportion of END bone was highest in the DECID age class, but across all ages END tissues comprised $<7 \%$ of total cortical area (SOM Table S-1).

\section{$<<<$ FIGURE 8 - PTROG QUAL OBSERVATIONS $\gg>$}

Qualitative observations. The DECID age class showed a prevalence of ECC and secondary intracortical (HAV) remodeling (SOM Fig. S-4a.). FLC-LZPO, with densely distributed longitudinal primary osteons, was observed in mid-cortical regions and was most prevalent in the smallest and least HAV-remodeled individual (MNHU 83618).

The M1 and M2 age classes showed an increase in the \% area of FLC-LZPO, and more variation in the vascularization of this tissue type. While many individuals showed a 
predominantly longitudinal vascular pattern, two individuals in the M2 age class showed an increase in the presence of circularly-oriented primary osteons in the medial and postero-medial cortex. In these latter individuals, circular canals regularly anastomosed with longitudinallyoriented vascular canals, forming a laminar FLC-LZPO tissue (Figs. 8A, B.) In all individuals, FLC-LZPO showed a regional distribution, observed predominantly in the medial cortex (SOM Figs. S-4b and c). FLC-LZPO decreased in the M3 and EPIPH age classes, where LAM with longitudinal vascular canals was more commonly observed.

Qualitative observation also revealed evidence of growth cycles at the midshaft femur. Individuals in the M2 and older age classes were characterized by multiple lines of arrested growth, distributed throughout the thickness of the periosteal cortex (Fig. 8C). These structures were more closely spaced in anterior and anterolateral cortices, and they became more widely spaced (often disappearing locally) in the medial cortex. In addition, several individuals in the M2 age class were characterized by alternations of LAM and FLC-LZPO tissue across the thickness of the primary periosteal cortex, particularly in the medial and adjacent cortical regions (SOM Fig. S-4c). In Figure 8C, growth layers comprised of FLC-LZPO and vascular LAM were interspersed with narrow layers of less vascular LAM and lines of arrested growth, producing a distinctly repetitive microstructural pattern.

Principal components analysis (PCA).

$$
\begin{gathered}
<<<\text { TABLES } 5 \text { and } 6-\text { PCA }>>> \\
<<<\text { FIGURE } 9-\text { PCA }>>>
\end{gathered}
$$

The first two principal components together accounted for $82.19 \%$ of the total variance in the sample (Tables 5 and 6, Fig. 9). PC 1 accounted for $56.11 \%$ of the total variance, and 
was most strongly correlated with proportions of lamellar-zonal tissue types. Negative values on PC 1 reflected increased PF and PF-LAM, while positive values reflected increased LAM. When supplemental variables were included, PC 1 was highly correlated with age class but not cortical area. PC 1 summarized a common age-related pattern within all taxa, characterized by a transition from PF bone in younger age classes to LAM bone in older age classes.

Several species-specific trends were also apparent along PC 1. In C. aethiops, the DECID age class was distributed negatively on PC 1, while individuals of all older age classes were distributed positively and exhibited considerable overlap. In $H$. lar, the DECID age class occupied the most negative extreme of PC 1, and showed some overlap with the M1 age class. The M2 and older age classes showed overlap and occupied the more positive end of its range. In P. troglodytes, the DECID age class loaded negatively along PC 1, the M1 and M2 age classes were intermediate, and older age classes loaded positively and overlapped in their distribution.

PC 2 accounted for $26.08 \%$ of the total variance. Negative values reflected increased proportions of END tissues, while positive values reflected increased FLC + FLC-LZPO. Taxa were most clearly distinguished from one another along PC 2, particularly for younger age classes. In $C$. aethiops, all DECID age class individuals were distributed more positively than all older age classes; two individuals (UCSC 62, 33) were outside the range of all other taxa. While M1 individuals were also distributed positively along this axis, older age classes overlapped in their distributions, reflecting the variable proportions of END tissue observed among individuals. H. lar was most commonly distributed negatively along PC 2, particularly in younger age classes, reflecting their higher proportions of END. In contrast, most $P$. troglodytes were distributed positively along PC 2, reflecting increased proportions of fibro-lamellar tissue types. Individuals in younger age classes showed variable distributions along PC 2, with single 
individuals in the DECID, M1 and M2 age classes occupying the upper half of the species' distribution (and overlapping with DECID C. aethiops). M3 and EPIPH individuals were distributed in the lower half of the $P$. troglodytes range.

\section{Discussion}

Primary bone tissues at the midshaft femur of catarrhine primates exhibit significant ontogenetic variability in features of their microscopic anatomy, which are understood to reflect variability in periosteal depositional rates. In the three taxa examined here, the youngest age classes were characterized by a significantly greater percent area of fibro-lamellar and parallelfibered bone tissue types, associated with the fastest depositional rates in prior experimental studies (Ricqlès et al., 1991; Castanet et al., 2004), while older age classes showed higher proportions of lamellar bone associated with slow depositional rates. Interestingly, taxonomic differences were observed in the timing of this transition, and in the particular tissue types observed among individuals of similar dental emergence status. In older age classes, higher proportions of parallel-fibered and fibro-lamellar tissue types were observed in those species that are reportedly characterized by faster body mass growth rates (H. lar and P. troglodytes) compared to slower-growing species (C. aethiops).

An important caveat in interpreting results of this study concerns the necessary limitations of its cross-sectional design, and its intent to infer growth processes from groups of individuals representing different age classes (and hence, developmental time points) (Tanner, 1990; Robinson et al., 2006). Thus, results concerning the timing of key changes in primary bone microstructure should be interpreted with some caution, as they are based on the assumption that age class differences are representative of intra-individual growth related 
changes (Robinson et al., 2006). An additional caveat includes the reliance on captive body mass growth patterns for generating predictions about bone microstructural development in this sample, which both differs in its population origin and is comprised of wild-collected individuals (e.g., see Altmann and Alberts, 1987; Turner et al., 1997; Hamada and Udono, 2002). Despite these limitations, and when evaluated in light of local circumstances of bone modeling and remodeling, taxonomic and ontogenetic patterns of primary bone microstructural development have significance for assessing species differences in somatic growth.

One distinction observed among taxa was the timing of lamellar bone deposition at the midshaft femur. In C. aethiops, the transition from deposition of fibro-lamellar tissue types to lamellar bone occurred during the first postnatal year (as estimated by dental emergence; Bolter and Zihlman, 2003); following first permanent molar emergence, individuals were characterized by an adult-like pattern in which lamellar bone comprised the majority of primary cortex area. This pattern is consistent with body mass velocity curves reported for captive vervet monkeys by Leigh (1996: Fig. 4, p. 462). In the latter study, males and females were characterized by maximum growth rates of approximately $1 \mathrm{~kg} /$ year immediately following birth, after which time growth velocities declined during the first postnatal year. In contrast, $H$. lar showed a more gradual transition, whereby an adult-like proportion of lamellar bone was not reached until after second molar emergence. Increased proportions of parallel-fibered tissue in the M1 age class of gibbons is in accordance with their reportedly faster body mass growth velocities compared to vervets during the first three years of life (Leigh and Shea, 1995; Leigh, 1996; Uchikoshi and Matsuzawa, 2007). We note that the midshaft humerus of these two taxa showed similar age and taxonomic patterns of primary bone microstructural development (McFarlin, 2006).

P. troglodytes was distinguished by increased proportions of fibro-lamellar bone during 
mid-ontogenetic stages, which is consistent with their faster body mass growth velocities compared to other taxa examined here (Leigh and Shea, 1995, 1996; Leigh, 1996). That fibrolamellar bone was found in middle and outer cortical regions (indicating more recent deposition) of the medial cortex indicates a sustained period of more rapid bone growth in the DECID, M1 and M2 age classes, compared to older age classes. Given small sample sizes, it was not possible to test for a significant increase in the percent area of fast-forming tissue types (namely fibrolamellar bone) in juvenile age classes, as may be predicted from prior research demonstrating that peak body mass growth velocities are reached at approximately 8.5 years of age in captivity (Leigh and Shea, 1995, 1996; Leigh, 1996). However, contrary to predictions, parallel-fibered and lamellar tissue types still comprised the majority of primary cortex area in chimpanzees of all age classes; these tissues had a parallel-fibered matrix component in the DECID age class, but were predominantly lamellar in older age classes.

In gibbons and chimpanzees, modeling and remodeling history at the midshaft femur had an important influence on the distribution of primary bone tissue types deposited during earlier growth stages. At all ages, gibbons and chimpanzees undergo significantly more secondary intracortical remodeling than vervet monkeys (McFarlin et al., 2008). Since this remodeling can be locally extensive and is preferentially distributed in inner cortical regions, affecting periosteal bone areas deposited during earlier growth stages, the proportions of parallel-fibered and fibrolamellar tissue types observed here likely underestimate the full extent of their deposition during ontogeny. Further, the influence of local modeling circumstances during early stages of bone microstructural development in gibbons and chimpanzees also warrants further investigation. Notably, the presence of endosteal compacted coarse cancellous bone and other features observed in $H$. lar are consistent with metaphyseal reduction, in which a coordinated pattern of 
periosteal bone resorption and endosteal deposition achieves the modeling of older metaphyseal regions as they are sequentially incorporated into the elongating diaphysis of a growing long bone (Enlow, 1962, 1963). Future sampling of other diaphyseal levels coincident with developmental midshaft may reveal higher proportions of tissue types associated with faster depositional rates (e.g., fibro-lamellar and/or more densely vascularized tissues). Singh (1974) reported primary bone with occasional radial vascular canals and "simple lamellae" in selected skeletal elements of a 2 year-old white-handed gibbon. Radial vascularization was not observed here, although such a pattern may indicate more rapid bone deposition (Margerie et al., 2004).

Finally, while the results summarized above demonstrate concordance between patterns of primary bone microstructural development and predictions based on reported patterns of somatic growth, we also note that other predictions of this study were unsupported. Within taxa, we found no significant sex differences in primary bone tissue type proportions. While the unknown sex of many individuals in our sample precluded testing of sexual dimorphism in chimpanzees, the lack of significant sex differences in vervet monkeys was unexpected. Prior examinations of the current study sample as well as other vervet populations have found that significant sex differences emerge during later stages of postnatal ontogeny in linear skeletal dimensions, cross-sectional geometry and body mass (Horrocks, 1986; Leigh, 1992, 1996; Turner et al., 1997; Bolter and Zihlman, 2003; McFarlin, 2006). Further, primary bone microstructure showed little change between the M1 and older age classes of vervets examined here, despite continuation of substantial growth in other skeletal and body dimensions in this sample (Bolter and Zihlman, 2003; McFarlin, 2006).

Qualitative observations of primary bone microstructural development in the sample 
Classification of bone into more broadly defined tissue 'types', as was done here, does not allow for the appreciation of more subtle variations in the microscopic organization of primary bone, which may also have significance for interpreting growth dynamics. In all three taxa, we observed variation among individuals in the density, size and/or orientation of vascular canals incorporated into primary periosteal tissues during growth, which prior experimental studies suggest may be associated with variation in bone depositional rates (Newell-Morris and Sirianni, 1982; Castanet et al., 1996, 2000; Margerie et al., 2002, 2004; Starck and Chinsamy, 2002). In chimpanzees, while longitudinal vascular canals were commonly observed across age classes, two individuals in the M2 age class were characterized by a dense arrangement of circularly and longitudinally oriented primary osteons, forming a laminar fibro-lamellar tissue. This latter tissue showed a patterned distribution in the medial and postero-medial cortex of the midshaft femur, an area interpreted to undergo differential periosteal growth associated with cortical drift. Prior vital labeling studies have indicated that the size and density of primary osteons is positively associated with bone depositional rates (Newell-Morris and Sirianni, 1982; Margerie et al., 2002; Starck and Chinsamy, 2002). However, the significance of vascular canal orientation for interpreting bone growth rate variability is debated, although it is generally accepted that longitudinally-vascularized bone is deposited at slower rates than other vascular sub-types (Castanet et al., 1996, 2000; Margerie, 2002; Margerie et al., 2002; Starck and Chinsamy, 2002; Margerie et al., 2004; Margerie et al., 2005; Lee and Simons, 2015). Whether deposition of laminar tissue in chimpanzees around M2 emergence reflects an increase in bone growth velocities, consistent with other characteristics of somatic growth (Hamada and Udono, 2002; Leigh and Shea, 1995, 1996; Leigh, 1996), warrants further investigation.

We also observed qualitative changes in the vascular network and other microanatomical 
features across the thickness of the periosteal cortex within individuals, which may have significance for discriminating seasonal or short-term temporal variability in bone growth rates (Ricqlès et al., 1991). Of particular note, we observed cement line structures termed 'lines of arrested growth' (LAGs), which record temporary cessations in bone growth, and 'annuli', understood to record temporary slow-downs in bone depositional rate (Peabody, 1961;

Francillon-Vieillot et al., 1990; Ricqlès et al., 1991; Castanet et al., 1993; Klevezal, 1996). They were expressed as thin lamellae, typically brighter than surrounding tissue when imaged in circularly polarized light (corresponding to annuli, as described by Castanet et al., 1993), or as resting cement lines (LAGs), distinguished by their contrast in brightfield illumination and their birefringence in CPL. LAGs could also be distinguished from the scalloped contour of reversal cement lines, which are often associated with cortical drift (Enlow, 1963), and by their location within the primary axis of periosteal growth. These features were ubiquitous in all taxa examined here, and they were commonly more numerous in older age classes than younger age classes.

LAGs and annuli have received considerable attention for their utility in assessing age at death, growth rates and maturational timing, based on the premise that they record annual and/or seasonally-mediated growth cycles in bone, and they figure prominently in attempts to reconstruct the life history strategies of dinosaurs and other extinct archosaurs (also see Peabody, 1961; Castanet et al., 1993, 2004; Chinsamy-Turan, 2005; Erickson, 2005; Köhler and MoyàSolà, 2009). However, while these growth marks have been observed in the mandible and long bone cortices of a wide range of vertebrates, including some mammals (reviews by Klevezal, 1996; Castanet, 2006), they are commonly assumed to be rare in large mammals (Erickson, 2005; but see Köhler and Moyà-Solà, 2009; Köhler et al., 2012). LAGs have been reported in human bone (Herrmann and Danielmeyer, 1994; Doppler et al., 2006; Cambra-Moo et al., 2012). 
In an experimental study, Castanet et al. (2004) demonstrated that the number of LAGs formed in the periosteal cortex was highly correlated with the number of seasonal photoperiod cycles experienced in captive gray mouse lemurs, thus demonstrating the potential utility of LAGs for recording annual cycles of bone growth in primates. Further, the latter authors also noted that formation of a single, more weakly expressed growth mark corresponded to the timing of weaning in these animals, suggesting that these structures may also reveal information about other biological processes in life history. Since observations of the current study indicate that LAGs may be more common in primate bone than often appreciated, these features warrant attention in future studies to better understand their etiology and other factors that influence their distribution in humans and nonhuman primates (Castanet, 2006). If they are determined to reflect the influence of seasonal cues, nutrition, or other environmentally mediated variation in bone growth rates, as suggested by research on other vertebrates, their study may offer insight into the evolution of plasticity in human and nonhuman primate growth (e.g., Kuzawa and Bragg, 2012).

Challenges and future directions: Significance of bone histology for research on human life history evolution

Compared to great apes, distinctive features of modern human life history include a late age at first reproduction, long post-reproductive lifespan, early age at weaning and short interbirth interval (Watts and Pusey, 1993; Hawkes and Paine, 2006), and a growth pattern characterized by a prolonged period of slow somatic growth between weaning and puberty, followed by a growth spurt in both body mass and linear dimensions that is comparatively late in onset and short in duration (Bogin and Smith, 1997; Leigh and Park, 1998; Leigh, 2001). This 
unique growth strategy is proposed to help individuals defer the energetic demands of an extended period of brain maturation and to help mothers support multiple overlapping and dependent offspring (Bogin, 2006; Gurven and Walker, 2006; Walker et al., 2006; Kuzawa et al., 2014). Much of our evidence concerning the evolutionary origins of human life history comes from dentition, which indicates that a modern human-like timescale of dental development emerged late in the evolution of our own genus, Homo (Dean and Smith, 2009; Smith et al., 2010; Schwartz, 2012). However, what of our unique pattern of somatic growth?

Our efforts to reconstruct body growth patterns in the past have relied on the availability of fossilized remains of immature individuals, which provide a snapshot of their developmental status at the time of death. For example, important evidence bearing on this question comes from an exceptionally complete skeleton of an immature male Homo erectus, KNM-WT 15000 (Smith, 1993). Early studies of this specimen suggested a disparity in skeletal and dental age-atdeath based on modern human standards (most recently estimated at $\sim 13.0$ versus 10.2 years, depending on which population standards are applied), with its skeletal maturity being considerably advanced for a modern human of similar dental maturation stage (Smith, 1993; Dean and Smith, 2009). Recent analyses incorporating data from dental histology yielded an age at death estimate for this individual of 7.6-8.8 years; this is more concordant with skeletal and dental age estimates derived from modern chimpanzee standards (Dean et al., 2001; Zihlman et al., 2004; Dean and Smith, 2009). Given the large estimated stature of the Nariokotome individual (Ruff and Walker, 1993; Ruff, 2007; Ruff and Burgess, 2015), these data fit a scenario in which H. erectus would have lacked the extended phase of low somatic growth rates during childhood that is characteristic of modern humans, and was instead characterized by a pattern of more rapid early growth (Dean and Smith, 2009). 
Results of the current study suggest that bone histology has potential to shed light on the evolutionary origins of the modern human somatic growth pattern. In previous studies of cortical bone microanatomical development in modern humans of documented age at death (Pfeiffer, 2006; Cuijpers, 2009; Goldman et al., 2009), lamellar bone was the predominant primary tissue type observed following infancy. However, fibro-lamellar bone was observed in infants/toddlers, and again reappeared in peri-pubescent children, indicating periods of more rapid bone growth. ${ }^{1}$ Based on the absence of fibro-lamellar bone, they concluded that bone depositional rates would have been lower during childhood compared to infancy and early adolescence in modern humans. In contrast, observations reported here of chimpanzees reveal a different pattern, in which fibro-lamellar tissue types comprised a considerable proportion of midshaft cortical area in all individuals representing the DECID, M1 and M2 age classes. These observations suggest that more rapid bone depositional rates may characterize early ontogeny in chimpanzees compared to modern humans, a pattern that is consistent with contrasts in their reported body mass growth (Leigh and Park, 1998; Walker et al., 2006).

Taken together, these observations suggest that the absence of fibro-lamellar bone formation may be a marker of the low childhood growth rates characteristic of modern humans, in contrast to the pattern observed in chimpanzees. To test the robustness of this pattern, future studies are critically needed to address a number of important limitations in our available data. First, existing studies of primary bone histology in modern humans and other primates are limited by the small samples available for histologic examination and, in the current analysis, by the lack of associated chronological age and sex. Small sample sizes within age classes also

\footnotetext{
${ }^{1}$ It is noted here that Cambra-Moo et al., 2012 and 2014 reported the presence of 'fibro-lamellar bone' in long bone cortices of juvenile humans of undocumented age. However, their criteria cited for identifying this tissue type (see Table 1, Cambra-Moo et al., 2012) differ from criteria employed in the current study. 'Fibro-lamellar bone' identified in juveniles depicted in Figure 3E-F in Cambra-Moo et al., 2012 appears only sparsely vascularized by primary osteons, and would likely have been identified as a vascularized lamellar bone here.
} 
precluded analyses of finer scale age and sex variation. Given the restricted comparative sample examined here, future work would also benefit substantially by the inclusion of additional taxa chosen to incorporate better contrasts for body size, phylogeny, locomotor behavior, growth patterns and life history (e.g., Hunt, 1991; Watts and Pusey, 1993; Leigh and Shea, 1995, 1996; Doran, 1996). Further, since genetics, nutrition, hormones, somatic growth and mechanical loading all have a complex and interactive influence on the growth, development and maintenance of bone (for a recent review, see Gosman, 2012), future studies that incorporate additional skeletal sites and that are designed to address the challenges of distinguishing ontogenetic, mechanically adaptive and evolutionary influences on primary bone histodiversity in primates are critically needed. In particular, while attention has tended to focus on secondary remodeling, the mechanical properties of different primary bone tissue types observed here are less well understood (Currey, 2002). Finally, future work is needed to examine the influence of taxonomic, ontogenetic, and age-related variability in secondary remodeling on the distribution of primary bone tissue types in human and nonhuman primate taxa (Schaffler and Burr, 1984; Burr et al., 1989; Paine and Godfrey, 1997; Mulhern and Ubelaker, 2003; Havill, 2004; McFarlin et al., 2008; Streeter, 2012). It is worth noting that while it is commonly assumed that human bone is extensively remodeled in the adult such that any record of early primary development is lost to subsequent remodeling, this assumption has been questioned (Bromage et al., 2011).

If these results are borne out in future research, and given recent advances in nondestructive imaging methods that can be applied to fractured bone surfaces (Bromage et al., 2005, 2009a) or complete specimens (Sanchez et al., 2012), bone histology has great potential as an important and independent line of inquiry into the evolution of human growth and development in the fossil record. Further, because bone microstructural development is 
influenced both by somatic growth processes and the local mechanical demands of its usage, bone histology may also reveal unique information about other aspects of behavior that impact energetics and survival throughout life history, for example, supporting efforts to explore relationships between dental and skeletal maturation and the ontogeny of locomotor behavior (Zihlman, 1992; Bezanson and Morbeck, 2013). Future approaches based on the examination of tooth and bone microstructural development in the same individuals may allow us not only to identify evolutionary shifts in dental development, but to examine key changes in the developmental rate and timing of other body and behavioral systems that are critical to a more comprehensive understanding of the evolutionary origins of modern human life history.

\section{Acknowledgements}

This research was inspired by the groundbreaking contributions of Donald H. Enlow, particularly in his efforts to meticulously document and understand bone histodiversity and its ontogenetic foundations. One of us (S.C.M.) had the great fortune of 'cutting teeth' in the world of bone histology by spending innumerable hours studying the impressive comparative slide collection Enlow amassed (now curated at the New York University College of Dentistry), and this research in particular benefitted immeasurably from his feedback as a Ph.D. committee member and colleague. This work was also substantially improved through discussions with and assistance from a number of others, including Johanna Warshaw, Haviva M. Goldman, Debra Bolter, Eric Delson, Fred Szalay, and Chet Sherwood, and from students and other researchers of the Hard Tissue Research Unit, New York Consortium of Evolutionary Primatology, and the Center for the Advanced Study of Human Paleobiology at The George Washington University. We also thank Haviva Goldman, Chet Sherwood and three anonymous reviewers for comments 
on earlier drafts of this manuscript. Skeletal materials from the Sherwood L. Washburn collection at the University of California Santa Cruz, the Museum of Comparative Zoology of Harvard University, and the Museum für Naturkunde of the Humboldt University were kindly made available for the current study; numerous individuals at these institutions also provided valuable assistance, including Maria Rutzmoser, Judy Chupasko, Manfred Ade, Peter Giere, Andrea Mess, Detlef Wilborn, and Irene Thomas. This research was supported by the National Science Foundation (SBE-DDIG 0202823; funding to NYCEP), The Leakey Foundation, and the City University of New York (Robert E. Gilleece Fellowship; Dissertation Fellowship). Support to S.C.M. was also provided by funding from The George Washington University's Selective Academic Excellence Initiative to CASHP. Partial research support was also provided by the 2010 Max Planck Research Award to T.G.B., endowed by the German Federal Ministry of Education and Research to the Max Planck Society and the Alexander von Humboldt Foundation in respect of the Hard Tissue Research Program in Human Paleobiomics.

\section{FIGURE LEGENDS}

Figure 1. Bone tissue types recognized in the current study. (A) Bone tissue types classified on the basis of collagen fiber matrix organization, imaged in circularly polarized light. For primary bone tissues shown here, less vascular and more highly ordered lamellar tissues are characterized by slower rates of osteogenesis than more loosely organized and highly vascular woven and fibro-lamellar bone tissues, as described in the text. (B) Bone tissue types defined on the basis of vascular canal orientation, imaged in brightfield microscopy. (C) Two additional tissue types are shown. Compacted coarse cancellous bone is an endosteally deposited tissue formed in bone areas originally comprised of coarse cancellous trabeculae. Intervening spaces 
between trabeculae are later in-filled with deposition of parallel-fibered or lamellar bone, giving this tissue type a distinctively convoluted appearance. Secondary osteonal (Haversian) bone is formed by the sequential resorption and deposition of bone at single sites within the cortex. Scale bar $=0.1 \mathrm{~mm}$ in width .

Figure 2. Tissue type maps. Shown here is a tissue type map of the midshaft femur of a juvenile Hylobates lar specimen (MCZ 41502). Areas representing different tissue types are color coded for quantitative analysis. Greens represent tissues of periosteal origin. Pink and orange colors represent tissues of endosteal origin. Within these color families, tissue types associated with faster rates of osteogenesis are represented by darker shades than slowerdeposited tissue types.

Figure 3. Scatterplots of tissue type proportions in C. aethiops, H. lar, and P. troglodytes. Scatterplots of the percentage of cortical area represented by different tissue types, by cortical area and categorized by age class: periosteal fibro-lamellar complex and transitional fibro-lamellar bone (FLC+LZPO), periosteal lamellar bone (LAM), and endosteal lamellar bone (ELAM).

Figure 4. Age class mean percentage of total cortical area represented by primary periosteal tissue types and total endosteal bone, in combined sex samples of $C$. aethiops, $H$. lar, and $\boldsymbol{P}$. troglodytes. Bars representing different tissue types are color coded to correspond with tissue type maps.

Figure 5. Representative examples of tissue type maps illustrating the development of primary bone microanatomy across age classes in $C$. aethiops, $H$. lar, and P. troglodytes. Areas representing different tissue types are color coded for quantitative analysis, as depicted in Figure 2. Dental age classes DECID - M3 are as defined in the text. Scale bar $=0.5 \mathrm{~mm}$ in 
width.

Figure 6. Development of bone microstructure across age classes at the midshaft

femur in C. aethiops. Same field-of-view tissue type maps (left: abbreviations follow Figure 2), circularly polarized light image (CPL) depicting changes in collagen fiber organization (middle), and brightfield microscopy image revealing vascular canals and osteocyte lacunae (right). (A) Posterolateral cortex of the midshaft femur. Individuals in the DECID age class are characterized by a more densely vascularized FLC or FLC-LZPO tissue type. Vascular canals are actively being incorporated in the growing bone matrix at the periosteal surface, as can be seen in the bottom of this field of view. The arrows indicate a single annulus visible in the middle cortex, characterized by a layer of less vascularized bone. (B) Posteromedial cortex and $(C)$ anterolateral cortex of individuals representing the M1 and M2 age classes, respectively. By eruption of the first permanent molar, the majority of the primary periosteal cortex is comprised of poorly vascularized LAM bone. Arrows denote prominent lines of arrested growth (LAGs), which can be identified based on their contrast in LM and birefringence in CPL. Note, the bright appearance of LAGs is less evident in LAM tissue having a predominantly transverse collagen fiber orientation. LAGs can be readily distinguished from preparation artifacts, such as cracks, as the latter tend to appear isotropic in CPL. Scale bar $=0.5 \mathrm{~mm}$ in width.

Figure 7. Development of bone microstructure across age classes at the midshaft femur in H. lar. Same field-of-view tissue type maps (left: abbreviations follow Figure 2), CPL image depicting changes in collagen fiber organization (middle), and brightfield microscopy image revealing vascular canals and osteocyte lacunae (right). (A) Anterior cortex of the midshaft femur. END and HAV, respectively, comprise the majority of the inner and middle regions of the cortex, while the outer cortex is comprised of PF-LAM. The arrow indicates the 
scalloped contour of a reversal cement line evident in the outermost cortex, representing a previous phase of resorption followed by deposition at the periosteal surface. (B) Posterolateral cortex. Individuals in the M1 age class show an intermediate microstructural pattern, characterized by roughly equal proportions of PF-LAM and LAM. This individual shows a markedly repetitive microstructural pattern, characterized by alternating layers of PF-LAM, LAM, and FLC-LZPO. Arrows indicate the locations of two lines of arrested growth, which appear brighter than surrounding tissue in polarized light. (C) Posterolateral cortex. Individuals of the $\mathrm{M} 3$ age class are characterized by a predominance of LAM bone in the primary periosteal cortex, which is sparsely vascularized with longitudinally-oriented simple primary vascular canals. This individual shows a common pattern for this taxon, whereby series of lamellae appearing dark in polarized light alternate with series of birefringent lamellae throughout the thickness of the periosteal cortex, indicating apparent changes in the preferred collagen fiber orientation of the matrix. Regions of bright lamellae were frequently associated with resting lines or annuli, as indicated by the arrows. Scale bar $=0.5 \mathrm{~mm}$ in width.

Figure 8. Development of bone microstructure across age classes at the midshaft

femur in P. troglodytes. Same field-of-view tissue type maps (left: abbreviations follow Figure 2), circularly polarized light image depicting changes in collagen fiber organization (middle), and brightfield microscopy image revealing vascular canals and osteocyte lacunae (right). (A) Medial cortex of the midshaft femur, showing a transition from FLC-LZPO to LAM bone, vascularized by primary osteons having a longitudinal orientation. $(B)$ Medial cortex, showing FLC-LZPO with a laminar vascular arrangement, characterized by a network of circularly arranged vascular canals that form anastomoses with longitudinal canals. HAV bone is observed in the inner cortex of this individual. (C) Anteromedial cortex of a second individual representing the $\mathrm{M} 2$ age class. 
The primary periosteal cortex is predominantly of a vascularized LAM tissue type. However, three distinct zones of FLC-LZPO deposition are also evident, each of which is preceded by less vascular LAM tissue and the formation of a line of arrested growth (see arrows). Scale bar $=0.5$ mm in width.

Figure 9. Principal components 1 and 2: midshaft femur of $C$. aethiops, $H$. lar and $P$. troglodytes. Top: Minimum convex polygons were drawn to delineate those age classes within taxa that show the greatest difference in their distribution along PC 1: DECID C. aethiops, DECID - M2 for H. lar, and DECID - M2 for P. troglodytes. (Data points representing DECID and M1 P. troglodytes individuals are indicated by arrows, since these age classes are represented by small sample sizes.) All other age classes show substantial overlap within taxa in their distribution along PC 1. Bottom left: Minimum polygons were drawn to delineate wholesample taxon distributions on PC 2. 


\section{REFERENCES}

Altmann, J., Alberts, S., 1987. Body mass and growth rates in a wild primate population. Oecologia 72, 15-20.

Altmann, J., Alberts, S., 2005. Growth rates in a wild primate population: ecological influences and maternal effects. Behav. Ecol. Sociobiol. 57, 490-501.

Amprino, R., 1947. La structure du tissu osseux envisagee comme expression de differences dans la vitesse de l'accroissement. Arch. Biologie 58, 316-330.

Amprino, R., Godina, G., 1947. La struttura delle osssa nei vertebrati: ricerche comparative negli anfibi e negli amnioti. Comment. Pontificia Academia Scientiarum 11(9).

Balena, R., Shih, M.-S., Parfitt, A.M., 1992. Bone resorption and formation on the periosteal envelope of the lium: a histomorphometric study in healthy women. J. Bone Miner. Res. 7, 1475-1482.

Bezanson, M., Morbeck, M.E., 2013. Future adults or old children? Integrating life history frameworks for understanding primate positional patterns. In: Clancy, K.B.H., Hinde, K., Rutherford, J.N. (Eds.), Building Babies: Primate Development in Proximate and Ultimate Perspective. Springer-Verlag, New York, pp. 435-458.

Bogin, B., 2006. Modern human life history: the evolution of human childhood and fertility. In: Hawkes, K., Paine, R.R. (Eds.), The Evolution of Human Life History. School of American Research Press, Santa Fe, pp. 197-230.

Bogin, B., Smith, B.H., 1997. Evolution of the human life cycle. Am. J. Hum. Biol. 8, 703-716.

Bolter, D.R., Zihlman, A.L., 2003. Morphometric analysis of growth and development in wildcollected vervet monkeys (Cercopithecus aethiops), with implications for growth patterns in Old World monkeys, apes and humans. J. Zool., Lond. 260, 99-110. 
Breuer, T., Breuer-Ndoundou Hockemba, M., Olejniczak, C., Parnell, R.J., Stokes, E.J., 2009. Physical maturation, life-history classes and age estimates of free-ranging western gorillas_insights from Mbeli Bai, Republic of Congo. Am. J. Primatol. 71, 106-119.

Brits, D., Steyn, M., L'Abbé, E.N., 2014. A histomorphological analysis of human and nonhuman femora. Int. J. Legal. Med. 128, 369-377.

Brockelman, W.Y., Reichard, U., Treesucon, U., Raemaekers, J.J., 1998. Dispersal, pair formation and social structure in gibbons (Hylobates lar). Behav. Ecol. Sociobiol. 42, 329-339.

Bromage, T.G., Dean, M.C., 1985. Re-evaluation of the age at death of immature fossil hominids. Nature 317, 525-527.

Bromage, T.G., Goldman, H.M., McFarlin, S.C., Warshaw, J., Boyde, A., Riggs, C.M., 2003. Circularly polarized light standards for investigations of collagen fiber orientation in bone. Anat. Rec. B. New. Anat. 274, 157-168.

Bromage, T.G., Perez-Ochoa, A., Boyde, A., 2005. Portable confocal microscope reveals fossil hominid microstructure. Microsc. Analysis 19, 5-7.

Bromage, T.G., Goldman, H.M., McFarlin, S.C., Perez Ochoa, A., Boyde, A., 2009a. Circularly polarized confocal scanning optical microscopy of a 3my Australopithecus afarensis femur. Scanning 31, 1-10.

Bromage, T.G., Lacruz, R.S., Hogg, R., Goldman, H.M., McFarlin, S.C., Warshaw, J., Dirks, W., Perez-Ochoa, A., Smolyar, I., Enlow, D.H., Boyde, A.. 2009b. Lamellar bone is an incremental tissue reconciling enamel rhythms, body size, and organismal life history. Calcif. Tissue Int. 84, 388-404. 
Bromage, T.G., Juwayeyi, Y.M., Smolyar, I., Hu, B., Gomez, S., Chisi, J. 2011. Enamelcalibrated lamellar bone reveals long period growth rate variability in humans. Cells Tissues Organs 194, 124-130.

Buffrénil, V. de, Pascal, M., 1984. Croissance et morphogenese postnatales de la mandibule du vision (Mustela vision Shreiber): donnees sur la dynamique et l'interpretation fonctionnelle des depots osseux mandibulaires. Can. J. Zool. 62, 2026-2037.

Burr, D.B., 1992. Estimated intracortical bone turnover in the femur of growing macaques: implications for their use as models in skeletal pathology. Anat. Rec. 232, 180-189.

Burr, D.B., Nishikawa, R.Y., Van Gerven, D., 1989. Bone growth and remodeling in Cayo Santiago - derived Macaca mulatta. P. R. Health Sci. J. 8, 191-196.

Cambra-Moo, O., Meneses, C.N., Barbero, M.Á.R., Gil, O.G., Pérez, J.R., Rello-Varona, S., Martín, M.C., Martín, A.G., 2012. Mapping human long bone compartmentalisation during ontogeny: a new methodological approach. J. Struct. Biol. 178, 338-349.

Cambra-Moo, O., Meneses, C.N., Barbero, M.Á.R., Gil, O.G., Pérez, J.R., Rello-Varona, S., D’Angelo, M., Martín, M.C., Martín, A.G., 2014. An approach to the histomorphological and histochemical variations of the humerus cortical bone through human ontogeny. J. Anat. 224, 634-646.

Castanet, J., 2006. Time recording in bone microstructures of endothermic animals; functional relationships. C. R. Palevol. 5, 629-636.

Castanet, J., Francillon-Vieillot, H., Meunier, F.J., de Ricqlès, A., 1993. Bone and individual aging. In: Hall, B.K. (Ed.), Bone. CRC Press, Boca Raton, pp. 245-284. 
Castanet, J., Grandin, A., Abourachid, A., de Ricqlès, A., 1996. Expression de la dynamique de croissance dans la structure de l'os périostique chez Anas platyrhynchos. C.R. Acad. Sci., Paris Série 3, Sciences de la vie 319, 301-308.

Castanet, J., Rogers, K.C., Cubo, J., Boisard, J.-J., 2000. Periosteal bone growth rates in extant ratites (ostrich and emu). Implications for assessing growth in dinosaurs. C.R. Acad. Sci., Paris Série 3, Sciences de la vie 323, 543-550.

Castanet, J., Cubo, J., de Margerie, E., 2001. Signification de l'histodiversité osseuse: le message de l'os. Biosystema 19, 133-147.

Castanet, J., Croci, S., Aujard, F., Perret, M., Cubo, J., de Margerie, E., 2004. Lines of arrested growth in bone and age estimation in a small primate: Microcebus murinus. J. Zool., Lond. 263, 31-39.

Chinsamy-Turan, A., 2005. The Microstructure of Dinosaur Bone. The Johns Hopkins University Press, Baltimore.

Cuijpers, S., 2009. Distinguishing between the bone fragments of medium-sized mammals and children. A histological identification method for archaeology. Anthropol. Anz. 67, 181203.

Currey, J.D., 2002. Bones: Structure and Mechanics. Princeton University Press, Princeton.

Dean, M.C., 2010. Retrieving chronological age from dental remains of early fossil hominins to reconstruct growth in the past. Phil. Trans. R. Soc., Lond. B 365, 3397-3410.

Dean, M.C., Smith, B.H., 2009. Growth and development of the Nariokotome youth, KNM-WT 15000. In: Grine, F.E., Fleagle, J.G., Leakey, R.E. (Eds,), The First Humans: Origins and Early Evolution of the Genus Homo: Springer Science + Business Media B.V., XX, pp. 101-120. 
Dean, M.C., Leakey, M.G., Reid, D., Schrenk, F., Schwartz, G.T., Stringer, C., Walker, A., 2001. Growth processes in teeth distinguish modern humans from Homo erectus and earlier hominins. Nature 414, 628-631.

Demeter, G., Mátyás, J., 1928. Mikroskopisch vergleichend-anatomische studien an röhrenknochen mit besonder rücksicht auf die unterscheidung menschlicher und tierischer knochen. Anat. Embryol. 87, 45-99.

Dirks, W., 2003. Effect of diet on dental development in four species of cararrhine primates. Am. J. Primatol. 61, 29-40.

Dirks, W., Bowman, J.E., 2007. Life history theory and dental development in four species of catarrhine primates. J. Hum. Evol. 53, 309-320.

Doppler, S., Hotz, G., Neuberger, F., Grupe, G., 2006. Bone microstructure and its hidden information. Anthropol. Anz. 64, 257-271.

Doran, D.M., 1996. Comparative positional behavior of the African apes. In: McGrew, W.C., Marchant, L.F., Nishida, T. (Eds.), Great Ape Societies. Cambridge University Press, Cambridge, pp. 213-224.

Drapeau, M.S., Streeter, M.A., 2006. Modeling and remodeling responses to normal loading in the human lower limb. Am. J. Phys. Anthropol. 129, 403-409.

Enlow, D.H., 1962. A study of the post-natal growth and remodeling of bone. Amer. J. Anat. $110,79-101$.

Enlow, D.H., 1963. Principles of Bone Remodeling: An Account of Postnatal Growth and Remodeling Processes in Long Bones and the Mandible. Charles C. Thomas, Springfield. 
Enlow, D.H., 1966. An evaluation of the use of bone histology and forensic medicine in anthropology. In: Evans, F.G. (Ed.), Studies on the Anatomy and Function of Bone and Joints. Springer-Verlag, New York, pp. 93-112.

Enlow, D.H., 1976. The remodeling of bone. Yearb. Phys. Anthropol. 20, 19-34.

Enlow, D.H., 1982. Handbook of Facial Growth. W.B. Saunders Company, Philadelphia.

Enlow, D.H., Brown, S.O., 1956. A comparative histological study of fossil and recent bone tissues. Part I. Tex. J. Sci. 8, 405-443.

Enlow, D.H., Brown, S.O., 1957. A comparative histological study of fossil and recent bone tissues. Part II. Tex. J. Sci. 9, 186-214.

Enlow, D.H., Brown, S.O., 1958. A comparative histological study of fossil and recent bone tissues. Part III. Tex. J. Sci. 10, 187-230.

Enlow, D.H., Hans, M.G., 1996. Essentials of Facial Growth. W.B. Saunders Company, Philadelphia.

Erickson, G.M., 2005. Assessing dinosaur growth patterns: a microscopic revolution. Trends Ecol. Evol. 20, 677-684.

Fedigan, L., Fedigan, L.M., 1988. Cercopithecus aethiops: a review of field studies. In: GautierHion, A., Bourliere, F., Gautier, J.-P., Kingdon, J. (Eds.), A Primate Radiation: Evolutionary Biology of the African Guenons. Cambridge University Press, Cambridge, pp. 389-411.

Feik, S., Thomas, C.D.L., Bruns, R., Clement, J.G., 2000. Regional variations in modeling in the femoral mid-shaft: sex and age differences. Am. J. Phys. Anthropol. 112, 191-206.

Foote, J.S., 1916. Contribution to the Comparative Histology of the Femur. Smithsonian Institution, Washington, D.C. 
Francillon-Vieillot, H., de Buffrénil, V., Castanet, J., Geraudie, J., Meunier, F.J., Sire, J.Y., Zylberberg, L., de Ricqlès, A., 1990. Microstructure and mineralization of vertebrate skeletal tissues. In: Carter, J.G. (Ed.), Skeletal Biomineralization: Patterns, Processes and Evolutionary Trends. Van Nostrand Reinhold, New York, pp. 471-530.

Frost, H.M., 1973. Bone Modeling and Skeletal Modeling Errors. Thomas, Springfield.

Frost, H.M., 1990a. Skeletal structural adaptations to mechanical usage (SATMU): 1. Redefining Wolff's law: The bone modeling problem. Anat. Rec. 226, 403-413.

Frost, H.M., 1990b. Skeletal structural adaptations to mechanical usage (SATMU): 2. Redefining Wolff's law: The remodeling problem. Anat. Rec. 226, 414-422.

Garn, S.M., Frisancho, A.R., Sandusky, S.T., McCann, M.B., 1972. Confirmation of the sex difference in continuing subperiosteal apposition. Am. J. Phys. Anthropol. 36, 377-380.

Godfrey, L.R., Samonds, K.E., Jungers, W.L., Sutherland, M.R., Irwin, M.T., 2004. Ontogenetic correlates of diet in Malagasy lemurs. Am. J. Phys. Anthropol. 123, 250-276.

Goldman, H.M., Kindsvater, J., Bromage, T.G., 1999. Correlative light and backscattered electron microscopy of bone - Part I: Specimen preparation methods. Scanning 21, 4043.

Goldman, H.M., Bromage, T.G., Thomas, C.D.L., Clement, J.G., 2003. Preferred collagen fiber orientation in the human mid-shaft femur. Anat. Rec., A 272A, 434-445.

Goldman, H.M., McFarlin, S.C., Cooper, D., Thomas, C.D.L., Clement, J.G., 2009. Ontogenetic patterning of cortical bone microstructure and geometry at the human mid-shaft femur. Anat. Rec. 292, 48-64.

Goodall, J., 1986. The Chimpanzees of Gombe: Patterns of Behavior. Harvard University Press, Cambridge. 
Gosman, J.H., 2012. Growth and development: morphology, mechanisms and abnormalities. In: Crowder, C., Stout, S.D. (Eds.), Bone Histology: An Anthropological Perspective. CRC Press, Boca Raton, pp. 23-44.

Gurven, M., Walker, R., 2006. Energetic demand of multiple dependents and the evolution of slow human growth. P. R. Soc. B 273, 835-841.

Hamada, Y., Udono, T., 2002. Longitudinal analysis of length growth in the chimpanzee (Pan troglodytes). Am. J. Phys. Anthropol. 118, 268-284.

Hamada, Y., Udondo, T., Teramoto, M., Sugawara, T., 1996. The growth pattern of chimpanzees: Somatic growth and reproductive maturation in Pan troglodytes. Primates $37,279-295$.

Havill, L.M., 2004. Osteon remodeling dynamics in Macaca mulatta: normal variation with regard to age, sex, and skeletal maturity. Calcif. Tissue Int. 74, 95-102.

Hawkes, K., Paine, R.R. (Eds.), 2006. The Evolution of Human Life History. School of American Research Press, Santa Fe.

Herrman, B., Danielmeyer, A., 1994. Bone structures reflecting rhythm, seasonality, and lifestyle of past human populations. Naturwissenschaften 81, 399-401.

Hillier, M.L., Bell, L.S., 2007. Differentiating human bone from animal bone: a review of histological methods. J. Forensic Sci. 52, 249-263.

Horrocks, J.A., 1986. Life-history characteristics of a wild population of vervets (Cercopithecus aethiops sabaeus) in Barbados, West Indies. Int. J Primatol. 7, 31-47.

Hunt, K.D., 1991. Positional behavior in the Hominoidea. Int. J Primatol.12, 95-118.

Jee, W.S.S., Tian, X.Y., Setterberg, R.B., 2007. Cancellous bone minimodeling-based formation: A Frost, Takahashi legacy. J. Musculoskel. Neur. Inter. 7, 232-239. 
Jowsey, J., 1966. Studies of Haversian systems in man and some animals. J. Anat. 100, 857-864.

Jowsey, J., 1968. Age and species differences in bone. Cornell Vet. 58, 74-94.

Kerley, E.R., 1966. Skeletal age changes in the chimpanzee. Tulane Stud. Zool. 13, 71-82.

Klevezal, G.A., 1996. Recording Structures of Mammals: Determination of Age and Reconstruction of Life History. A.A. Balkema, Rotterdam.

Köhler, M., Moyà-Solà, S., 2009. Physiological and life history strategies of a fossil large mammal in a resource-limited environment. Proc. Natl. Acad. Sci. 106, 20354-20358.

Köhler, M., Marín-Moratalla, N., Jordana, X., Aanes, R., 2012. Seasonal bone growth and physiology in endotherms shed light on dinosaur physiology. Nature 487, 358-361.

Kuzawa, C.W., Bragg, J.M., 2012. Plasticity in human life history strategy: implications for contemporary human variation and the evolution of genus Homo. Curr. Anthropol. 53, S369-S382.

Kuzawa, C.W., Chugani, H.T., Grossman, L.I., Lipovich, L., Muzik, O., Hof, P.R., Wildman, D.E., Sherwood, C.C., Leonard, W.R., Lange, N., 2014. Metabolic costs and evolutionary implications of human brain development. Proc. Natl. Acad. Sci. 111, 13010-13015.

Lee, A.H., Simons, E.L.R., 2015. Wing bone laminarity is not an adaptation for torsional resistance in bats. PeerJ 3:e823.

Legendre, L., Roy, N.L., Montes, L., Laurin, M., Cubo, J., 2013. Phylogenetic signal in bone histology of amnoites revisited. Zool. Scr. 42, 44-53.

Leigh, S.R., 1992. Patterns of variation in the ontogeny of primate body size dimorphism. J. Hum. Evol. 23, 27-50.

Leigh, S.R., 1996. Evolution of human growth spurts. Am. J. Phys. Anthropol. 101, 455-474.

Leigh, S.R., 2001. Evolution of human growth. Evol. Anthropol. 10, 223-236. 
Leigh, S.R., Bernstein, R.M., 2006. Ontogeny, life history, and maternal investment in baboons. In: Swedell, L., Leigh, S.R. (Eds.), Reproduction and Fitness in Baboons: Behavioral, Ecological, and Life History Perspectives. Springer, New York, pp. 225-255.

Leigh, S.R., Blomquist GE. 2007. Life history. In: Campbell, C.J., Fuentes, A., MacKinnon, K.C., Panger, M., Bearder, S. (Eds.), Primates in Perspective. Oxford University Press, New York, pp. 396-407.

Leigh, S.R., Park, P.B., 1998. Evolution of human growth prolongation. Am. J. Phys. Anthropol. $107,331-350$.

Leigh, S.R., Shea, B.T., 1995. Ontogeny and the evolution of adult body size dimorphism in apes. Am. J. Primatol. 36, 37-60.

Leigh, S.R., Shea, B.T., 1996. Ontogeny of body size variation in African apes. Am. J. Phys. Anthropol. 99, 43-65.

Leighton, D.R., 1987. Gibbons: territoriality and monogamy. In: Smuts, B.B., Cheney, D.L., Seyfarth, R.M., Wrangham, R.W., Struhsaker, T.T. (Eds.), Primate Societies. University of Chigaco Press, Chicago, pp. 135-145.

Lieberman, D.E., Pearson, O.M., Polk, J.D., Demes, B., Crompton, A.W., 2003. Optimization of bone growth and remodeling in response to loading in tapered mammalian limbs. J. Exp. Biol. 206, 3125-3135.

Maggiano, C.M., 2012. Making the mold: a microstructural perspective on bone modeling during growth and mechanical adaptation. In: Crowder, C., Stout, S.D. (Eds.), Bone Histology: An Anthropological Perspective. CRC Press, Boca Raton, pp. 45-90. 
Maggiano, I.S., Maggiano, C.M., Tiesler, V., Kierdorf, H., Stout, S.D., Schultz, M., 2011. A distinct region of microarchitectural variation in femoral compact bone: histomorphology of the endosteal lamellar pocket. Int. J. Osteoarchaeol. 21, 743-750.

Margerie, E. de, 2002. Laminar bone as an adaptation to torsional loads in flapping flight. J. Anat. 201, 521-526.

Margerie, E. de, Cubo, J., Castanet, J., 2002. Bone typology and growth rate: testing and quantifying 'Amprino's rule' in the mallard (Anas platyrhynchos). C.R. Biologie 325, 221230.

Margerie, E. de, Robin, J.-P., Verrier, D., Cubo, J., Groscolas, R., Castanet, J., 2004. Assessing a relationship between bone microstructure and growth rate: a fluorescent labelling study in the king penguin chick (Aptenodytes patagonicus). J. Exp. Biol. 207, 869-879.

Margerie, E. de, Sanchez, S., Cubo, J., Castanet, J., 2005. Torsional resistance as a principal component of the structural design of long bones: comparative multivariate evidence in birds. Anat. Rec. A 282A, 49-66.

Martin, R.B., Burr, D.B., Sharkey, N.A., 1998. Skeletal Tissue Mechanics. Springer, New York. McFarlin, S.C., 2006. Ontogenetic variation in long bone microstructure in catarrhines and its significance for life history research . Ph.D. Dissertation, City University of New York.

McFarlin, S.C., Terranova, C.J., Zihlman, A.L., Enlow, D.H., Bromage, T.G., 2008. Regional variability in secondary remodeling within long bone cortices of catarrhine primates: the influence of bone growth history. J. Anat. 213, 308-324.

Moro, M., van der Meulen, M.C.H., Kiratli, B.J., Marcus, R., Bachrach, L.K., Carter, D.R., 1996. Body mass is the primary determinant of midfemoral bone acquisition during adolescent growth. Bone 19, 519-526. 
Mulhern, D.M., Ubelaker, D.H., 2003. Histologic examination of bone development in juvenile chimpanzees. Am. J. Phys. Anthropol. 122, 127-133.

Mulhern, D.M., Ubelaker, D.H., 2012. Differentiating human from non-human bone microstructure. In: Crowder, C., Stout, S.D. (Eds.), Bone Histology: An Anthropological Perspective. CRC Press, Boca Raton, pp. 109-134.

Newell-Morris, L., Sirianni, J.E., 1982. Parameters of bone growth in the fetal and infant macaque (Macaca nemestrina) humerus as documented by trichromatic bone labels. In: Dixon, A.D., Sarnat, B.G. (Eds.), Factors and Mechanisms Influencing Bone Growth. Alan R. Liss, Inc., New York, pp. 243-258.

Ortner, D.J., 2003. Identification of Pathological Conditions in Human Skeletal Remains. Academic Press, San Diego.

Padian, K., 2013. Why study the bone microstructure of fossil tetrapods? In: Padian, K., Lamm, E.-T. (Eds.), Bone Histology of Fossil Tetrapods: Advancing Methods, Analysis, and Interpretation. University of California Press, Berkeley, pp. 1-12.

Padian, K,. de Ricqlès, A., and Horner JR. 2001. Dinosaurian growth rates and bird origins. Nature 412, 405-408.

Paine, R.R., Godfrey, L.R., 1997. The scaling of skeletal microanatomy in non-human primates. J. Zool., Lond. 241, 803-821.

Parfitt, A.M., 1983. The physiological and clinical significance of bone histomorphometric data. In: Recker, R.R. (Ed.), Bone Histomorphometry: Techniques and Interpretation. CRC Press, Boca Raton, pp. 143-223.

Parfitt, A.M., 2002. Perspective: Parathyroid hormone and periosteal bone expansion. J. Bone Miner. Res. 17, 1741-1743. 
Peabody, F.E., 1961. Annual growth zones in living and fossil vertebrates. J. Morphol.108, 1162.

Pearson, O.M., Lieberman, D.E., 2004. The aging of Wolff's "law": Ontogeny and responses to mechanical loading in cortical bone. Am. J. Phys. Anthropol. Suppl 39, 63-99.

Pereira, M.E., Leigh, S.R., 2003. Modes of primate development. In: Kappeler, P.M., Pereira, M.E. (Eds.), Primate Life Histories and Socioecology. University of Chicago Press, Chicago, pp. 149-176.

Pfeiffer, S., 2006. Cortical bone histology in juveniles. In: Grupe, G., Peters, J. (Eds.), Documenta Archaeobiologiae Band. Verlag Marie Leidorf, Rahden/Westf., pp. 15-28.

Pritchard, J.J., 1972. General histology of bone. In: Bourne, G.H. (Ed.), The Biochemistry and Physiology of Bone, Second Edition. Academic Press, New York, pp. 1-20.

Pusey, A.E., 1978. The physical and social development of wild adolescent chimpanzees (Pan troglodytes schweinfurthii). Ph.D. Dissertation, Stanford University.

Quekett, J.T., 1855. Structure of the skeleton of vertebrate animals. Descriptive and illustrated catalogue of the histological series contained in the Museum of the Royal College of Surgeons of England. Volume 1. R. and J.E. Taylor, London.

Ricqlès, A. de, 1969. Recherches paléohistologiques sur les os longs des tétrapodes. II. Quelques observations sur la structure des os longs des thériodontes. Ann. .Paléontol., Vertébrés 55, 1-52.

Ricqlès, A. de, 1975. Recherches paléohistologiques sur les os longs des tétrapodes. VII. Sur la classification, la signification fonctionnelle et l'histoire des tissus osseux des tétrapodes. Première partie: structures. Ann. .Paléontol., Vertébrés 61, 51-129. 
Ricqlès, A. de, 1977. Recherches paléohistologiques sur les os longs des tétrapodes. VII. Sur la classification, la signification fonctionnelle et l'histoire des tissus osseux des tétrapodes. Deuxième partie: fonctions (fin). Ann. .Paléontol., Vertébrés 63, 133-160.

Ricqlès, A. de, 1993. Some remarks on palaeohistology from a comparative evolutionary point of view. In: Grupe, G., Garland, A.N. (Eds.), Histology of Ancient Human Bone: Methods and Diagnosis. Springer-Verlag, Berlin, pp. 37-77.

Ricqlès, A. de, 2007. Fifty years after Enlow and Brown's comparative histological study of fossil and recent bone tissues (1956-1958): A review of Professor Donald H. Enlow’s contribution to palaeohistology and comparative histology of bone. C.R. Palevol. 6, 591601.

Ricqlès, A. de, Meunier, F.J., Castanet, J., Francillon-Vieillot, H., 1991. Comparative microstructure of bone. In: Hall, B.K. (Ed.), Bone. CRC Press, Boca Raton, pp. 1-78.

Robinson, K., Schmidt, T., Teti, D.M., 2006. Issues in the use of longitudinal and cross sectional designs. In: Teti, D.M. (Ed.), Handbook of Research Methods in Developmental Science. Wiley-Blackwell, Cambridge, pp. 3-20.

Ruff, C.B., 2007. Body size prediction from juvenile skeletal remains. Am. J. Phys. Anthropol. $133,698-716$.

Ruff, C.B., Burgess, M.L., 2015. How much more would KNM-WT 15000 have grown? J. Hum. Evol. 80, 74-82.

Ruff, C.B., Walker, A., 1993. Body size and body shape. In: Leakey, R.E., Walker, A. (Eds.), The Nariokotome Homo erectus Skeleton. Harvard University Press, Cambridge, pp. 234-265. 
Ruff, C.B., Walker, A., Trinkaus, E., 1994. Postcranial robusticity in Homo. III: Ontogeny. Am. J. Phys. Anthropol. 93, 35-54.

Sanchez, S., Ahlberg, P.E., Trinajstic, K.M., Mirone, A., Tafforeau, P., 2012. Three-dimensional synchrotron virtual paleohistology: a new insight into the world of fossil bone microstructures. Microsc. Anal. 18, 1095-1105.

Saunders, S.R., 1985. Surface and cross-sectional comparisons of bone growth remodeling. Growth 49, 105-130.

Schaffler, M.B., Burr, D.B., 1984. Primate cortical bone microstructure: Relationship to locomotion. Am. J. Phys. Anthropol. 65, 191-197.

Schultz, A.H., 1944. Age changes and variability in gibbons: a morphological study on a population sample of a man-like ape. Am. J. Phys. Anthropol. 2, 1-129.

Schwartz, G.T., 2012. Growth, development, and life history throughout the evolution of Homo. Curr. Anthropol. 53(S6), S395-S408.

Singh, I.J., Tonna, E.A., Gandel, C.P., 1974. Comparative histological study of mammalian bone. J. Morphol. 144, 421-438.

Skedros, J.G., Kiser, C.J., Keenan, K.E., Thomas, S.C., 2011. Analysis of osteon morphotype scoring schemes for interpreting load history: evaluation in the chimpanzee femur. J. Anat. 218, 480-499.

Smith, B.H., 1992. Life history and the evolution of human maturation. Evol. Anthropol. 1, 134142.

Smith, B.H., 1993. The physiological age of KNM WT 15000. In: Walker, A., Leakey, R. (Eds.), The Nariokotome Homo erectus Skeleton. Harvard University Press, Cambridge, pp. 195-220. 
Smith, B.H., Boesch, C., 2011. Mortality and the magnitude of the "wild effect" in chimpanzee tooth emergence. J. Hum. Evol. 60, 34-46.

Smith, J.W., 1961. Collagen fibre patterns in mammalian bone. J. Anat. 94, 329-344.

Smith, R.J., Leigh, S.R., 1998. Sexual dimorphism in primate neonatal body mass. J. Hum. Evol. 34, 173-201.

Smith, T.M., Tafforeau, P., Reid, D.J., Pouech, J., Lazzari, V., Zermeno, J.P., Guatelli-Steinberg, D., Olejniczak, A.J., Hoffman, A., Radovčić, J., Makaremi, M., Toussaint, M., Stringer, C., Hublin, J,-J,. 2010. Dental evidence for ontogenetic differences between modern humans and neanderthals. Proc. Natl. Acad. Sci. 107, 20923-20928.

Sokal, R.R., Rohlf, F.J., 1995. Biometry. W.H. Freeman and Company, New York.

Starck, J.M., Chinsamy, A., 2002. Bone microstructure and developmental plasticity in birds and other dinosaurs. J. Morphol. 254, 232-246.

Streeter, M.A., 2012. Histological age-at-death estimation. In: Crowder, C., Stout, S.D. (Eds)., Bone Histology: An Anthropological Perspective. CRC Press, Boca Raton, pp. 135-152.

Tanner, J.M., 1990. Fetus into Man: Physical Growth from Conception to Maturity. Harvard University Press, Cambridge.

Turner, T.R., Anapol, F., Jolly, C.J., 1997. Growth, development, and sexual dimorphism in vervet monkeys (Cercopithecus aethiops) at four sites in Kenya. Am. J. Phys. Anthropol. 103, 19-35.

Uchikoshi. M., Matsuzawa, T., 2007. Tooth eruption in two agile gibbons (Hylobates agilis). Gibbon J. 3, 66-73. 
van der Meulen, M.C., Ashford, M.W., Jr., Kiratli, B.J., Bachrach, L.K., Carter, D.R., 1996. Determinants of femoral geometry and structure during adolescent growth. J. Orthop. Res. 14, 22-29.

Walker, R., Hill, K., Burger, O., Hurtado, A.M., 2006. Life in the slow lane revisited: Ontogenetic separation between chimpanzees and humans. Am. J. Phys. Anthropol. 129, 577-583.

Warshaw, J., 2007. Primate bone microstructural variability: relationships to life history, mechanical adaptation and phylogeny. Ph.D. Dissertation, City University of New York. Warshaw, J., 2008. Comparative primate bone microstructure: records of life history, function and phylogeny. In: Sargis, E.J., Dagosto, M. (Eds.), Mammalian Evolutionary Morphology: A Tribute to Frederick S. Szalay. Springer Verlag, Netherlands, pp. 385425 .

Watts, D.P., Pusey, A.E., 1993. Behavior of juvenile and adolescent great apes. In: Pereira, M.E., Fairbanks, L.A. (Eds.), Juvenile Primates: Life History, Development and Behavior. Oxford University Press, Oxford, New York, pp. 148-167.

Watts, E.S., 1990. Evolutionary trends in primate growth and development. In: DeRousseau, C.J. (Ed.), Primate Life History and Evolution. Wiley-Liss, Inc, New York, pp. 89-104.

White, T.D., Black, M.T., Folkens, P.A., 2011. Human Osteology. Academic Press, San Diego. Yen, P.K.J., Shaw, J.H., 1977. Remodeling of compact bone studied with lead acetate as an intravital stain. J. Dent. Res. 56, 961-966.

Yen, P.K.H., Moin, K., Shaw, J.H., 1978. Remodeling of cancellous bone in young monkeys. J. Dent. Res. 57, 388-394. 
Zihlman, A.L., 1992. Locomotion as a life history character: the contribution of anatomy. J. Hum. Evol. 22, 315-325.

Zihlman, A., Bolter, D., Boesch, C., 2004. Wild chimpanzee dentition and its implications for assessing life history in immature hominin fossils. Proc. Natl. Acad. Sci. 101, 1054110543. 
Table 1. Ontogenetic characteristics of the study taxa.

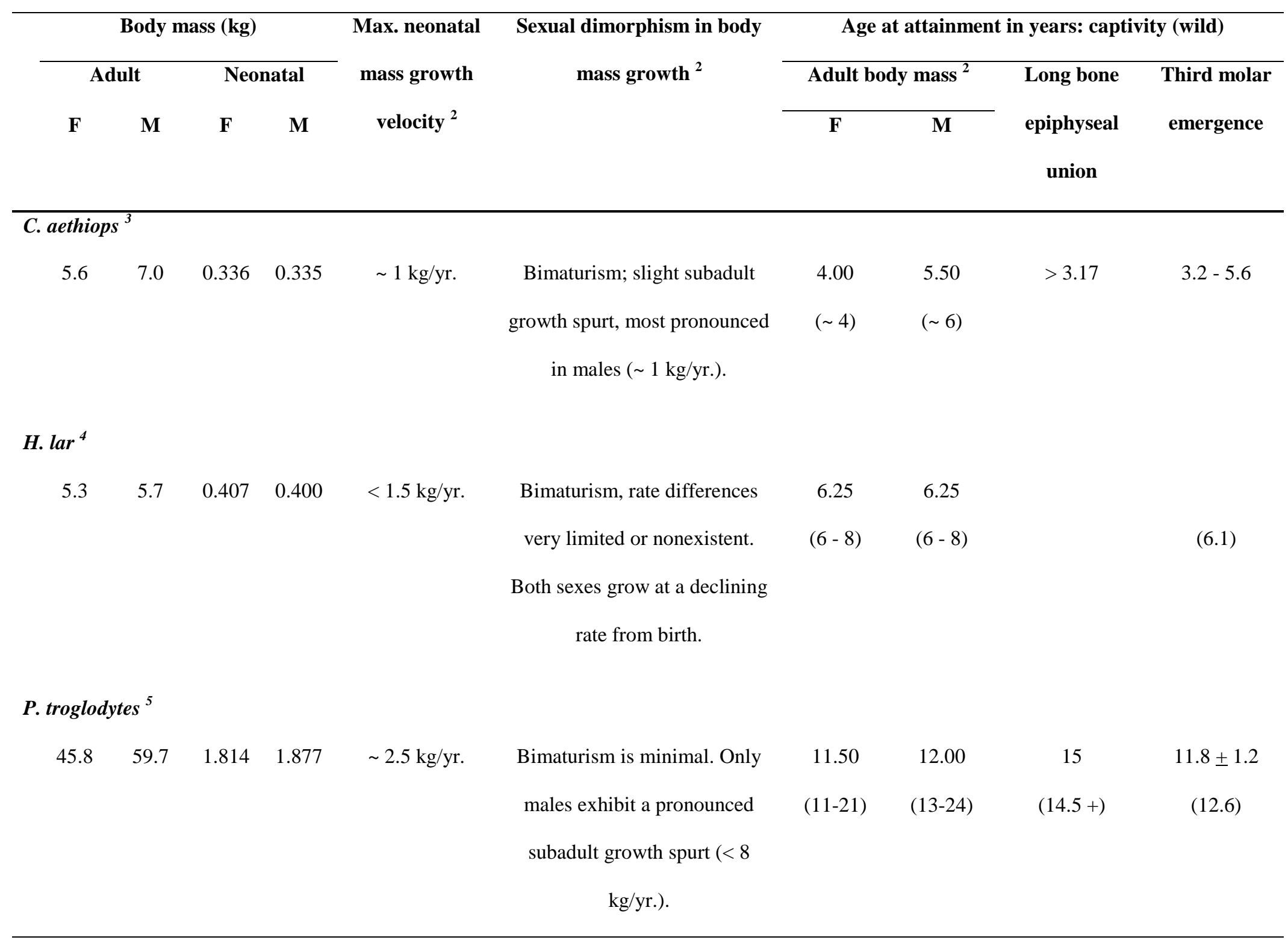


${ }^{1}$ Source for mean neonatal body mass data summarized here: (Smith and Leigh, 1998).

${ }^{2}$ While there are some reports based on wild individuals (e.g., Pusey, 1978; Turner et al., 1997; Bolter and Zihlman, 2003), body mass growth data summarized here are from studies of captive animals of known chronological age (Leigh, 1992; Leigh, 1996; Leigh and Shea, 1995; Leigh and Shea, 1996). Age at attainment of adult body mass in captive animals is from Leigh (1992).

${ }^{3}$ Additional sources for C. aethiops: mean adult body mass (Fedigan and Fedigan, 1988); age at adult body mass in wild animals (Horrocks, 1986; Fedigan and Fedigan, 1988); age at epiphyseal union and complete dentition (Bolter and Zihlman, 2003). It is noted here that mean adult body mass for the current sample was as follows: Males $=6.1 \mathrm{~kg}, n=3$; Females $=3.3 \mathrm{~kg}, n=3$.

${ }^{4}$ Additional sources for H. lar: mean adult body mass (Schultz, 1944); age at adult body size in wild animals (Leighton, 1987; Brockelman et al., 1998); age at mandibular M3 emergence in one individual (Dirks, 2003).

${ }^{5}$ Additional sources for P. troglodytes: mean adult body mass (Smith and Jungers, 1997; based on P. t. troglodytes); age at adult body size in wild animals (Pusey, 1978; Goodall, 1986; Pusey et al. 2005); age at epiphyseal union (Kerley, 1966; Zihlman et al., 2007); age at complete dentition based on captive grand mean \pm SD for maxillary M3 emergence (Smith and Boesch, 2011) and available wild data (Zihlman et al., 2004; Smith and Boesch, 2011). Pusey et al. (2005) note that while female body mass growth continues until 21 years of age, the phase of most rapid growth ends at 11 years; for males, growth velocity declines after age 13 years, but body mass continues to increase until 24 years of age. 
Table 2. Sample representation across biological age classes.

\begin{tabular}{|c|c|c|c|c|c|c|}
\hline Sex & $\begin{array}{c}\text { Total } \\
n\end{array}$ & $\begin{array}{l}\text { DECID } \\
\text { (Infant) }\end{array}$ & $\begin{array}{c}\text { M1 } \\
\text { (Juv. 1) }\end{array}$ & $\begin{array}{c}\text { M2 } \\
\text { (Juv. 2) }\end{array}$ & $\begin{array}{c}\text { M3 } \\
\text { (Juv. 3) }\end{array}$ & $\begin{array}{l}\text { EPIPH } \\
\text { (Adult) }\end{array}$ \\
\hline \multicolumn{7}{|c|}{ Chlorocebus (Cercopithecus) aethiops (SLW-UCSC) } \\
\hline $\mathrm{F}$ & 14 & 1 & 4 & 2 & 4 & 3 \\
\hline M & 16 & 4 & 1 & 4 & $4^{1}$ & 3 \\
\hline \multicolumn{7}{|c|}{ Hylobates lar (SLW-UCSC, MCZ) } \\
\hline $\mathrm{F}$ & 13 & 2 & 2 & 2 & $4^{2}$ & 3 \\
\hline M & 15 & 2 & 1 & 4 & 5 & 3 \\
\hline \multicolumn{7}{|c|}{ Pan troglodytes (MfN) } \\
\hline $\mathrm{F}$ & 5 & 1 & 0 & 1 & 3 & 0 \\
\hline M & 2 & 0 & 0 & 1 & 0 & 1 \\
\hline unk. & 5 & 1 & 1 & $2^{3}$ & 0 & 1 \\
\hline
\end{tabular}

\footnotetext{
${ }^{1}$ Includes one individual for which associated craniodental material was missing; assigned to M3 age class based on diaphyseal length and epiphyseal union.

${ }^{2}$ Includes two individuals for which associated craniodental material was missing; assigned to M3 age class based on diaphyseal length and epiphyseal union.

${ }^{3}$ Includes one individual having a questionable association with a skull having only permanent M1s emergent and unemergent M2s; reassigned to M2 age class based on diaphyseal length, as described in McFarlin (2006).
} 
Table 3. Spearman correlation statistics for tissue type proportions with age class and cortical area (bone area determined by pixel dimensions). Significant contrasts at $p \leq 0.05$ are bolded.

\begin{tabular}{|c|c|c|c|c|c|c|c|c|}
\hline \multirow[b]{2}{*}{ Variable } & \multicolumn{4}{|c|}{ Age Class } & \multicolumn{4}{|c|}{ Cortical Area } \\
\hline & $n$ & $r$ & $\mathrm{t}(n-2)$ & $p$ & $n$ & $r$ & $t(n-2)$ & $p$ \\
\hline \multicolumn{9}{|l|}{ C. aethiops } \\
\hline$\% \mathrm{FLC}$ & 30 & -0.69 & -4.98 & 0.000 & 30 & -0.66 & -4.61 & 0.000 \\
\hline$\%$ FLC-LZPO & 30 & -0.87 & -9.48 & 0.000 & 30 & -0.79 & -6.93 & 0.000 \\
\hline$\% \mathrm{FLC}+\mathrm{LZPO}$ & 30 & -0.87 & -9.48 & 0.000 & 30 & -0.80 & -6.97 & 0.000 \\
\hline$\% \mathrm{PF}$ & 30 & -0.40 & -2.28 & 0.031 & 30 & -0.46 & -2.75 & 0.010 \\
\hline$\%$ PF-LAM & 30 & -0.77 & -6.45 & 0.000 & 30 & -0.81 & -7.27 & 0.000 \\
\hline$\%$ LAM & 30 & 0.48 & 2.88 & 0.007 & 30 & 0.47 & 2.78 & 0.010 \\
\hline$\%$ EPF & 30 & -0.16 & -0.87 & 0.390 & 30 & -0.13 & -0.70 & 0.487 \\
\hline$\%$ EPF-LAM & 30 & 0.14 & 0.77 & 0.448 & 30 & 0.08 & 0.45 & 0.655 \\
\hline$\%$ ELAM & 30 & 0.58 & 3.77 & 0.001 & 30 & 0.66 & 4.64 & 0.000 \\
\hline$\%$ ECCC & 30 & 0.61 & 4.12 & 0.000 & 30 & 0.62 & 4.13 & 0.000 \\
\hline$\% \mathrm{HAV}$ & 30 & 0.62 & 4.15 & 0.000 & 30 & 0.67 & 4.73 & 0.000 \\
\hline \multicolumn{9}{|l|}{ H. lar } \\
\hline$\% \mathrm{FLC}$ & 28 & -0.28 & -1.47 & 0.153 & 28 & -0.22 & -1.13 & 0.268 \\
\hline$\%$ FLC-LZPO & 28 & -0.86 & -8.69 & 0.000 & 28 & -0.83 & -7.62 & 0.000 \\
\hline$\% \mathrm{FLC}+\mathrm{LZPO}$ & 28 & -0.86 & -8.77 & 0.000 & 28 & -0.83 & -7.52 & 0.000 \\
\hline$\% \mathrm{PF}$ & 28 & -0.68 & -4.71 & 0.000 & 28 & -0.65 & -4.32 & 0.000 \\
\hline$\%$ PF-LAM & 28 & -0.89 & -9.70 & 0.000 & 28 & -0.87 & -8.94 & 0.000 \\
\hline$\%$ LAM & 28 & 0.67 & 4.63 & 0.000 & 28 & 0.62 & 3.98 & 0.000 \\
\hline$\% \mathrm{EPF}$ & 28 & -0.43 & -2.46 & 0.021 & 28 & -0.45 & -2.56 & 0.017 \\
\hline$\%$ EPF-LAM & 28 & -0.73 & -5.43 & 0.000 & 28 & -0.72 & -5.36 & 0.000 \\
\hline$\%$ ELAM & 28 & -0.45 & -2.59 & 0.016 & 28 & -0.54 & -3.25 & 0.003 \\
\hline
\end{tabular}




\begin{tabular}{lcccccccc} 
\%ECCC & 28 & -0.65 & -4.40 & $\mathbf{0 . 0 0 0}$ & 28 & -0.55 & -3.36 & $\mathbf{0 . 0 0 2}$ \\
\%HAV & 28 & -0.01 & -0.07 & 0.946 & 28 & 0.08 & 0.40 & 0.690 \\
& & & & & & & & \\
P. troglodytes & & & & & & & & \\
\%FLC & 12 & -0.42 & -1.47 & 0.174 & 12 & -0.28 & -0.94 & 0.369 \\
\%FLC-LZPO & 12 & -0.73 & -3.38 & $\mathbf{0 . 0 0 7}$ & 12 & -0.71 & -3.16 & $\mathbf{0 . 0 1 0}$ \\
\%FLC + LZPO & 12 & -0.77 & -3.86 & $\mathbf{0 . 0 0 3}$ & 12 & -0.74 & -3.49 & $\mathbf{0 . 0 0 6}$ \\
\%PF & 12 & -0.66 & -2.81 & $\mathbf{0 . 0 1 9}$ & 12 & -0.64 & -2.63 & $\mathbf{0 . 0 2 5}$ \\
\%PF-LAM & 12 & -0.57 & -2.19 & 0.054 & 12 & -0.67 & -2.86 & $\mathbf{0 . 0 1 7}$ \\
\%LAM & 12 & 0.59 & 2.31 & $\mathbf{0 . 0 4 3}$ & 12 & 0.70 & 3.09 & $\mathbf{0 . 0 1 1}$ \\
\%EPF & 12 & -0.66 & -2.81 & $\mathbf{0 . 0 1 8}$ & 12 & -0.68 & -2.96 & $\mathbf{0 . 0 1 4}$ \\
\%EPF-LAM & 12 & -0.86 & -5.42 & $\mathbf{0 . 0 0 0}$ & 12 & -0.83 & -4.62 & $\mathbf{0 . 0 0 1}$ \\
\%ELAM & 12 & 0.30 & 1.00 & 0.340 & 12 & 0.22 & 0.73 & 0.484 \\
\%ECCC & 12 & -0.05 & -0.17 & 0.865 & 12 & 0.09 & 0.27 & 0.792 \\
\%HAV & 12 & 0.01 & 0.03 & 0.973 & 12 & -0.13 & -0.42 & 0.681 \\
\hline & & & & & & & & \\
\hline
\end{tabular}


Table 4. Kruskal-Wallis and Median tests: \% area of PER tissue types among AGE CLASSES. Significant contrasts in bold ( $p \leq 0.05)$. Mann-Whitney post-hoc contrasts reported here are significant at the $p \leq 0.05$ and $p \leq 0.10$ levels after Bonferroni correction.

\begin{tabular}{|c|c|c|c|c|c|c|c|c|}
\hline \multirow[b]{2}{*}{ \% Tissue Type } & \multirow[b]{2}{*}{ df } & \multirow[b]{2}{*}{$n$} & \multicolumn{2}{|c|}{ Kruskal-Wallis } & \multicolumn{2}{|c|}{ Median test } & \multirow{2}{*}{$\begin{array}{l}\text { Significant post-hocs } \\
\qquad\left(p^{\prime}=0.005\right)^{1}\end{array}$} & \multirow[t]{2}{*}{ Significant post-hocs $\left(p^{\prime}=0.010\right)^{1}$} \\
\hline & & & $\mathbf{H}$ & $p$ & Chi-Square & $p$ & & \\
\hline \multicolumn{9}{|c|}{ Chlorocebus aethiops } \\
\hline FLC & 4 & 30 & 24.10 & 0.000 & 25.00 & 0.000 & $\mathrm{DE}^{*} \mathrm{M} 3$ & $\mathrm{DE} * \mathrm{M} 2, \mathrm{DE} * \mathrm{EP}$ \\
\hline FLC-LZPO & 4 & 30 & 23.46 & 0.000 & 17.17 & 0.002 & $\mathrm{DE} * \mathrm{M} 3, \mathrm{M} 1 * \mathrm{M} 3$ & $\mathrm{DE} * \mathrm{M} 1, \mathrm{DE} * \mathrm{M} 2, \mathrm{DE} * \mathrm{EP}, \mathrm{M} 1 * \mathrm{EP}$ \\
\hline FLC +FLC- LZPO & 4 & 30 & 23.46 & 0.000 & 17.17 & 0.002 & $\mathrm{DE} * \mathrm{M} 3, \mathrm{M} 1 * \mathrm{M} 3$ & $\mathrm{DE} * \mathrm{M} 1, \mathrm{DE}^{*} \mathrm{M} 2, \mathrm{DE} * \mathrm{EP}, \mathrm{M} 1 * \mathrm{EP}$ \\
\hline $\mathrm{PF}$ & 4 & 30 & 7.83 & 0.098 & 5.22 & 0.265 & & \\
\hline PF-LAM & 4 & 30 & 18.81 & 0.001 & 17.17 & 0.002 & $\mathrm{DE} * \mathrm{M} 3, \mathrm{M} 1 * \mathrm{M} 3$ & $\mathrm{DE} * \mathrm{EP}$ \\
\hline LAM & 4 & 30 & 13.26 & 0.010 & 7.03 & 0.134 & & $\mathrm{DE}^{*} \mathrm{M} 1, \mathrm{DE} * \mathrm{M} 3, \mathrm{DE} * \mathrm{EP}$ \\
\hline Total END & 4 & 30 & 9.68 & 0.046 & 11.47 & 0.022 & & $\mathrm{DE} * \mathrm{M} 3$ \\
\hline \multicolumn{9}{|l|}{ Hylobates lar } \\
\hline FLC & 4 & 28 & 3.90 & 0.420 & 4.13 & 0.389 & & \\
\hline FLC-LZPO & 4 & 28 & 22.25 & 0.000 & 18.44 & 0.001 & $\mathrm{M} 2 * \mathrm{M} 3, \mathrm{M} 2 * \mathrm{EP}$ & $\mathrm{DE} * \mathrm{M} 3$ \\
\hline FLC+FLC-LZPO & 4 & 28 & 22.12 & 0.000 & 18.44 & 0.001 & $\mathrm{M} 2 * \mathrm{M} 3, \mathrm{M} 2 * \mathrm{EP}$ & $\mathrm{DE} * \mathrm{M} 3$ \\
\hline $\mathrm{PF}$ & 4 & 28 & 24.34 & 0.000 & 23.92 & 0.000 & & $\mathrm{DE} * \mathrm{M} 3$ \\
\hline PF-LAM & 4 & 28 & 21.98 & 0.000 & 18.44 & 0.001 & $\mathrm{M} 2 * \mathrm{M} 3, \mathrm{M} 2 * \mathrm{EP}$ & $\mathrm{DE}^{*} \mathrm{M} 3$ \\
\hline LAM & 4 & 28 & 16.02 & 0.003 & 9.33 & 0.053 & & $\mathrm{DE} * \mathrm{M} 3$ \\
\hline Total END & 4 & 28 & 15.53 & 0.004 & 10.44 & 0.034 & & $\mathrm{DE}^{*} \mathrm{M} 3$ \\
\hline
\end{tabular}


${ }^{1}$ Age class abbreviations: DECID (DE); M1 (M1); M2 (M2); M3 (M3); EPIPH (EP). 
Table 5. Principal components analysis. Variance contained within the entire dataset is summarized here for the first five principal component axes. Active input variables for calculation of principal components included $\%$ of total cortical area of END, and the $\%$ of primary periosteal cortex area represented by FLC + LZPO, PF, PF-LAM, and LAM.

\begin{tabular}{ccccc}
\hline & & \% Total & Cumulative & Cumulative \\
PC & Eigenvalue & variance & Eigenvalue & variance \\
\hline 1 & 2.806 & 56.11 & 2.81 & 56.11 \\
2 & 1.304 & 26.08 & 4.11 & 82.19 \\
3 & 0.537 & 10.74 & 4.65 & 92.93 \\
4 & 0.345 & 6.90 & 4.99 & 99.82 \\
5 & 0.009 & 0.18 & 5.00 & 100.00 \\
\hline
\end{tabular}

Table 6. Principal components analysis: factor loadings. Age class and cortical area were included as supplemental variables.

\begin{tabular}{lccccc}
\hline Variable & PC 1 & PC 2 & PC 3 & PC 4 & PC 5 \\
\hline \% END & -0.40 & -0.76 & 0.51 & 0.08 & 0.00 \\
\% per FLC+FLC-LZPO & -0.58 & 0.74 & 0.33 & 0.11 & 0.05 \\
\% per PF & -0.80 & -0.25 & -0.37 & 0.39 & 0.02 \\
\% per PF-LAM & -0.87 & -0.21 & -0.17 & -0.42 & 0.04 \\
\% per LAM & 0.96 & -0.28 & -0.05 & 0.05 & 0.07 \\
\hline \hline Age Class & 0.79 & -0.23 & 0.01 & 0.13 & 0.25 \\
Cortical area & 0.28 & 0.18 & -0.01 & 0.15 & 0.25 \\
\hline
\end{tabular}


FIGURE 1

A. Patterns of collagen fiber organization imaged in circularly polarized light (CPL).

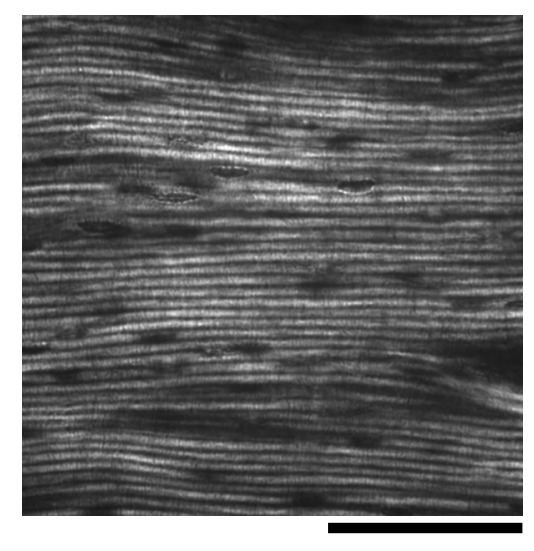

Lamellar bone

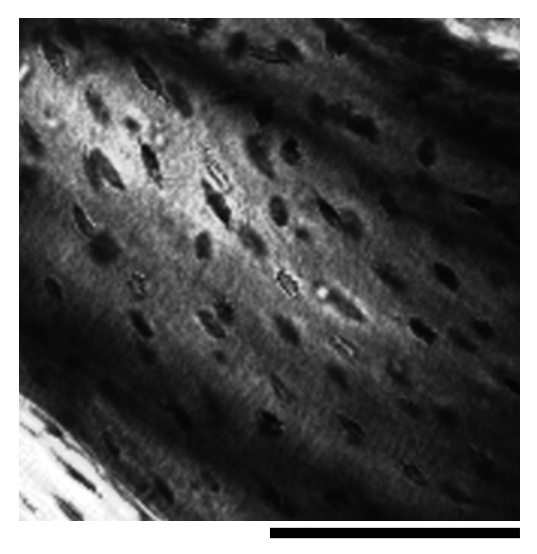

Parallel-fibered bone

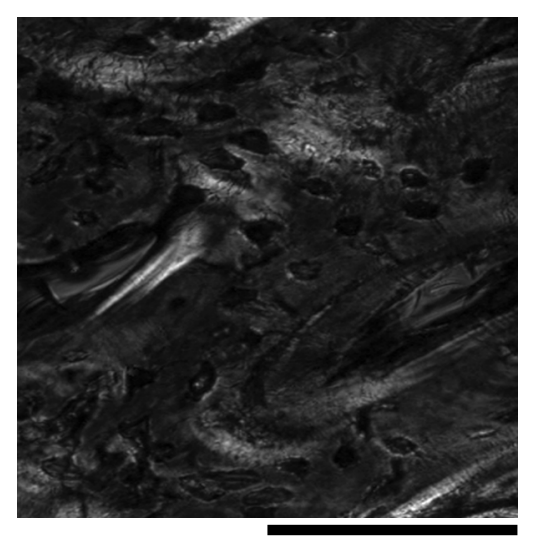

Woven bone

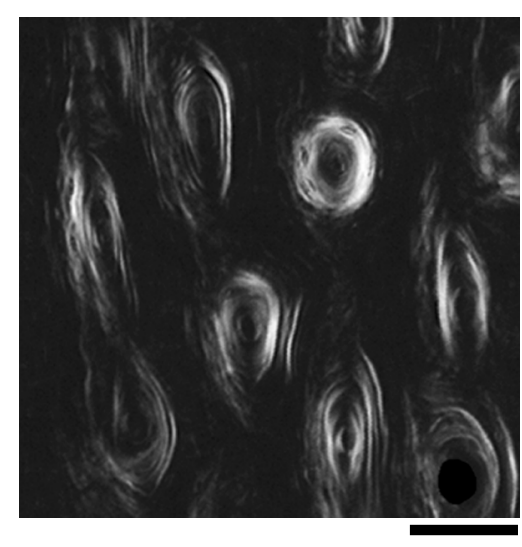

Fibro-lamellar bone

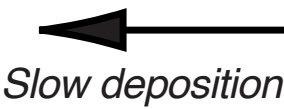

Fast deposition

B. Vascular patterns imaged in brightfield (LM).

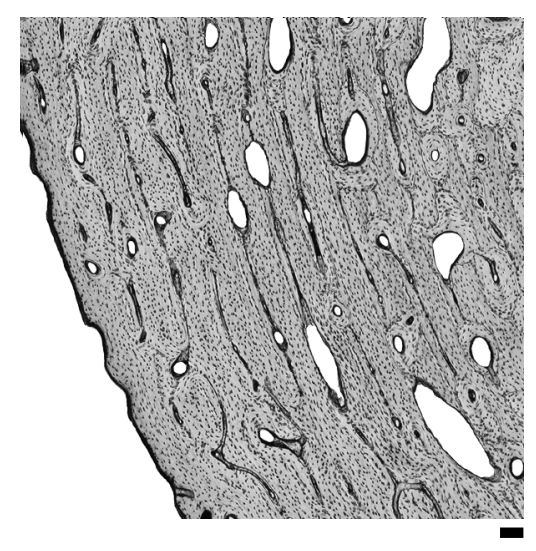

Laminar

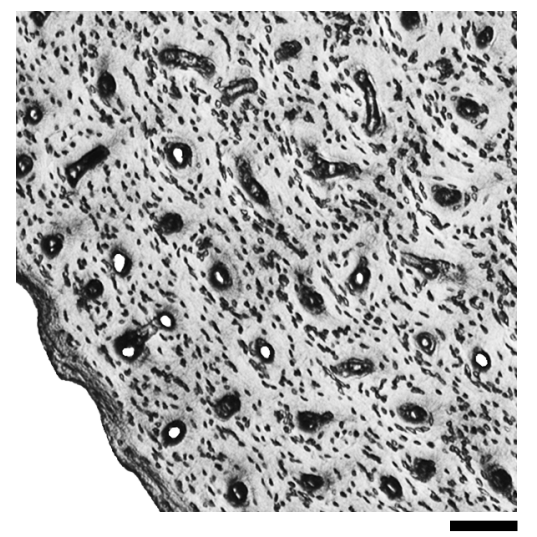

Longitudinal

C. Other tissue types imaged in CPL.

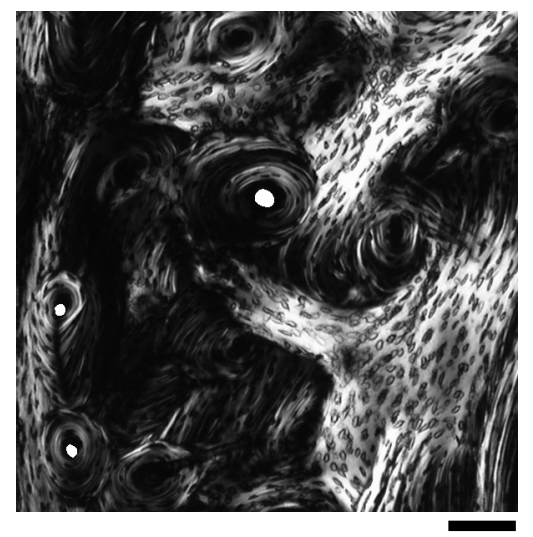

Endosteal compacted coarse cancellous

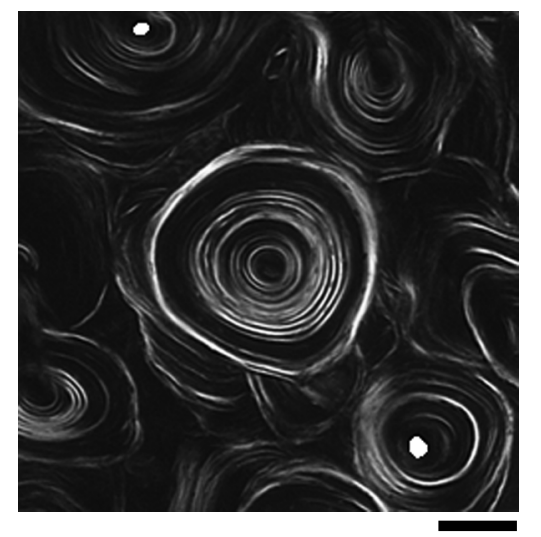

Secondary osteonal (Haversian) bone 


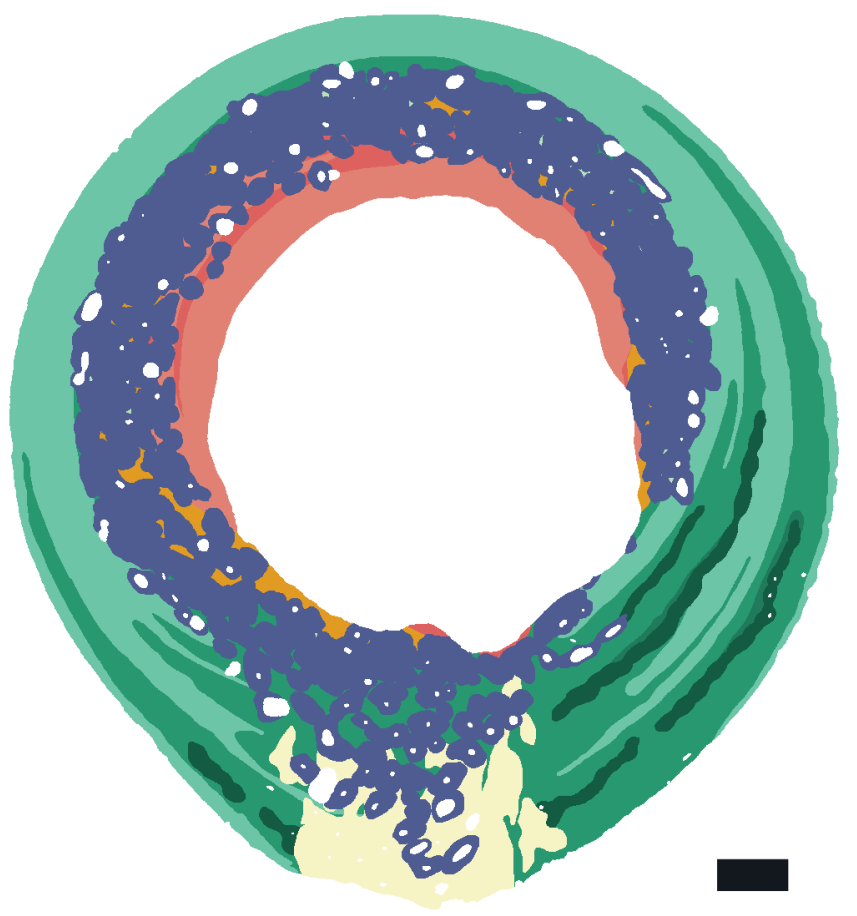

\section{Primary periosteal origin}

Fibro-lamellar complex (FLC)

$\square$ Transitional FLC (FLC-LZPO)

$\square$ Parallel-fibered (PF)

$\square$ Transitional PF to LAM (PF-LAM)

$\square$ Lamellar (LAM)

\section{Endosteal origin}

$\square$ Parallel-fibered (EPF)

$\square$ Transitional PF to LAM (EPF-LAM)

$\square$ Lamellar (ELAM)

$\square$ Compacted coarse cancellous (ECC)

\section{Other tissue types}

Secondary osteonal bone (HAV)

Sharpey's fiber bone (SF) 


\section{FIGURE 3}

\section{Chlorocebus aethiops}
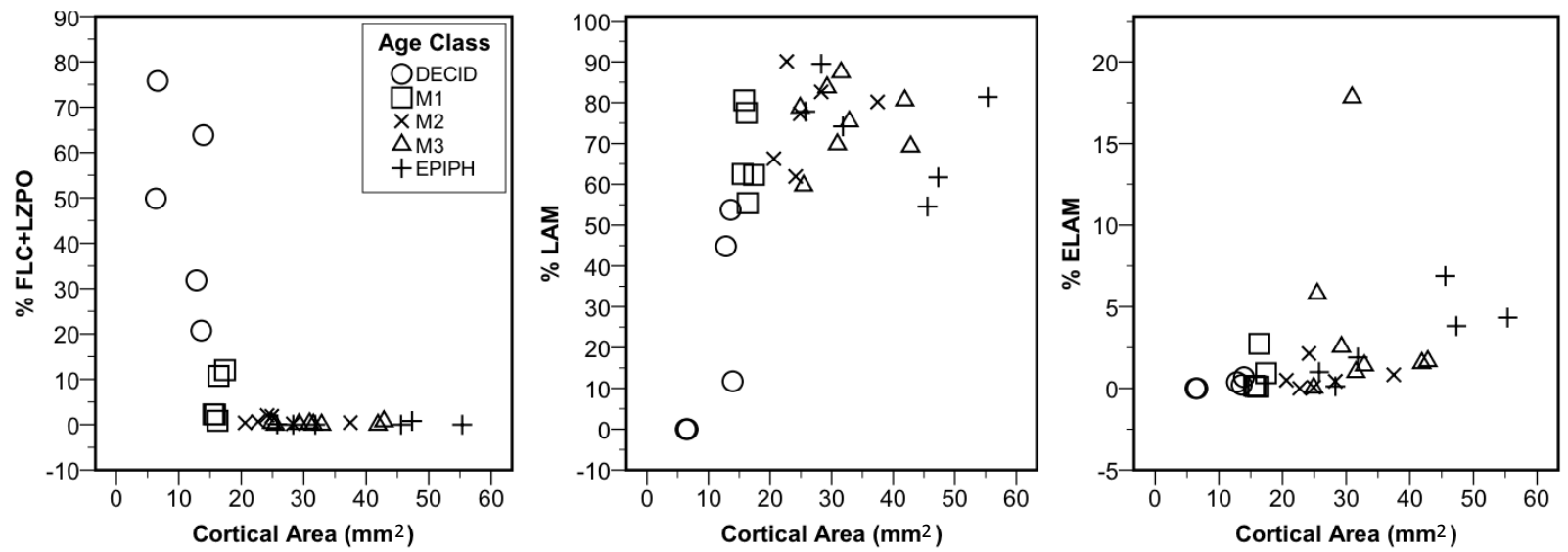

\section{Hylobates lar}
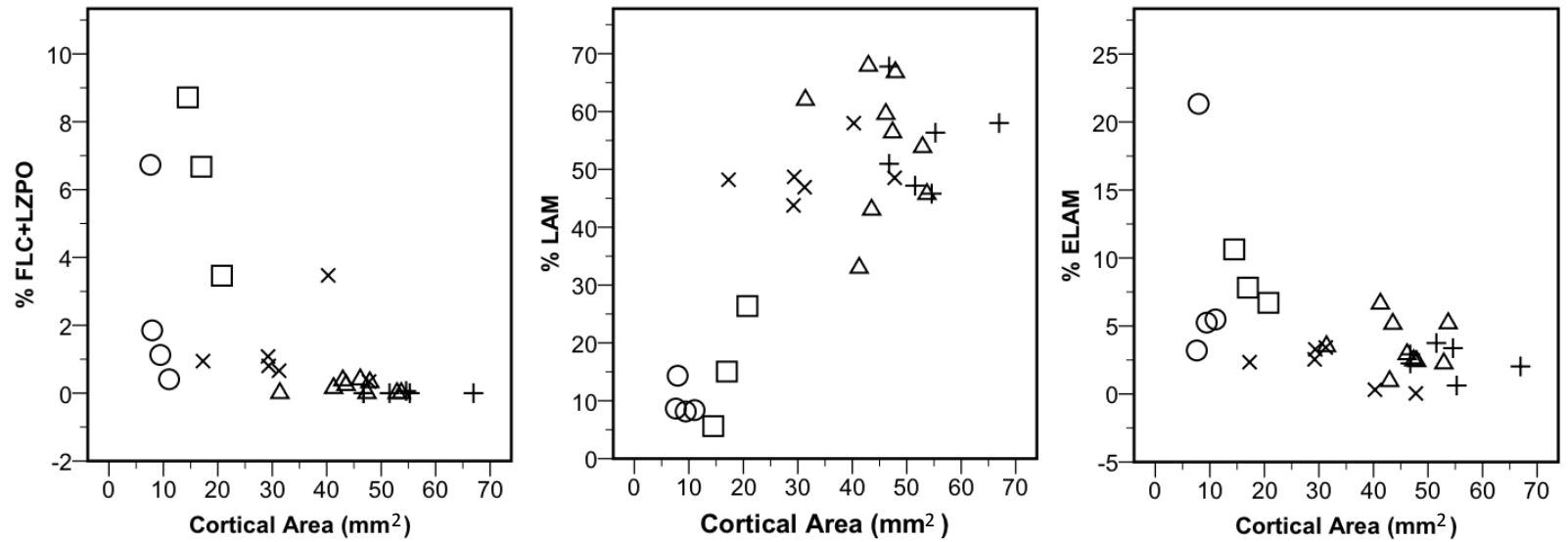

\section{Pan troglodytes}
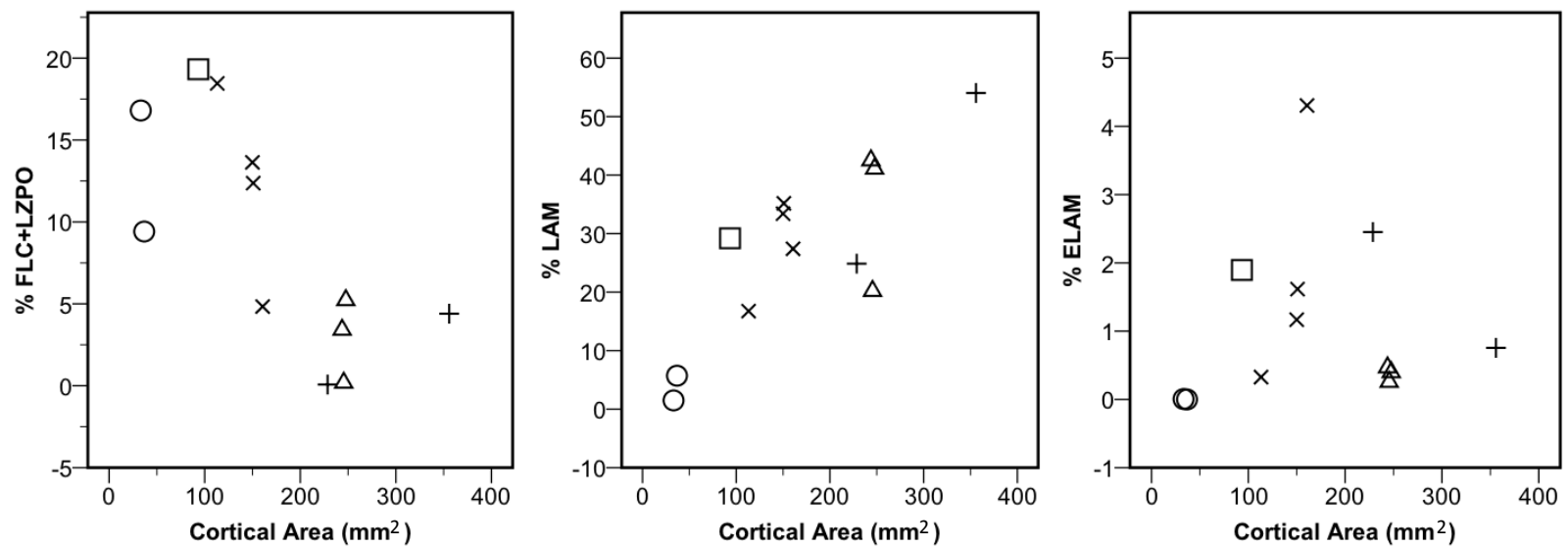
Chlorocebus aethiops

FIGURE 4

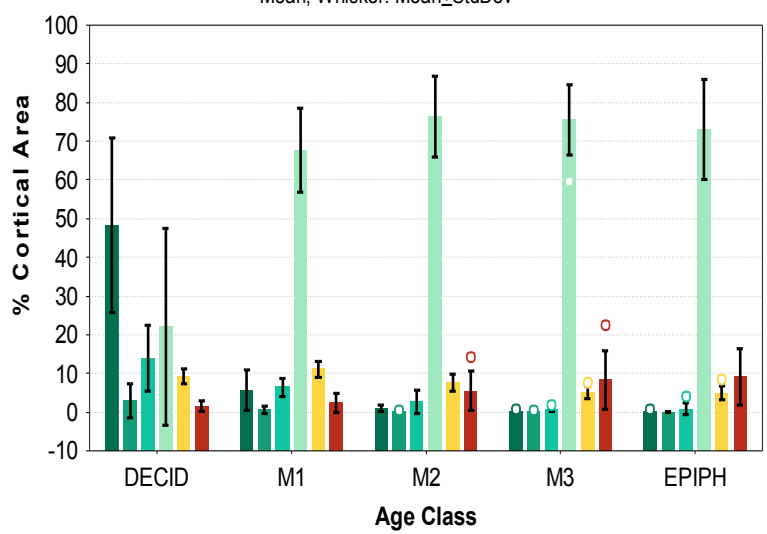

Hylobates lar

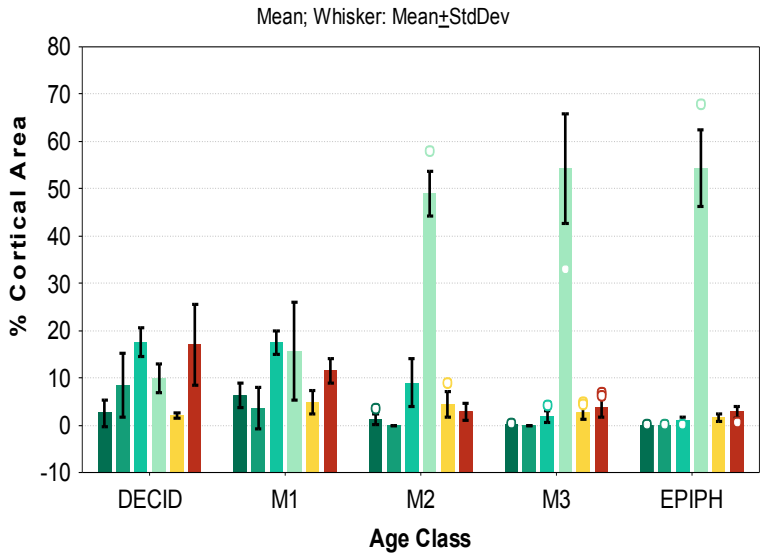

Pan troglodytes

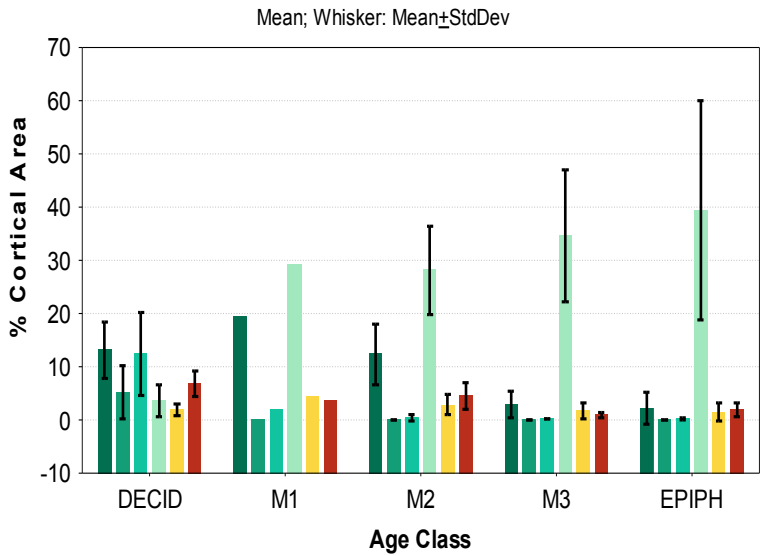

$\% \mathrm{FLC}+\mathrm{FLC}-\mathrm{LZPO}$ 


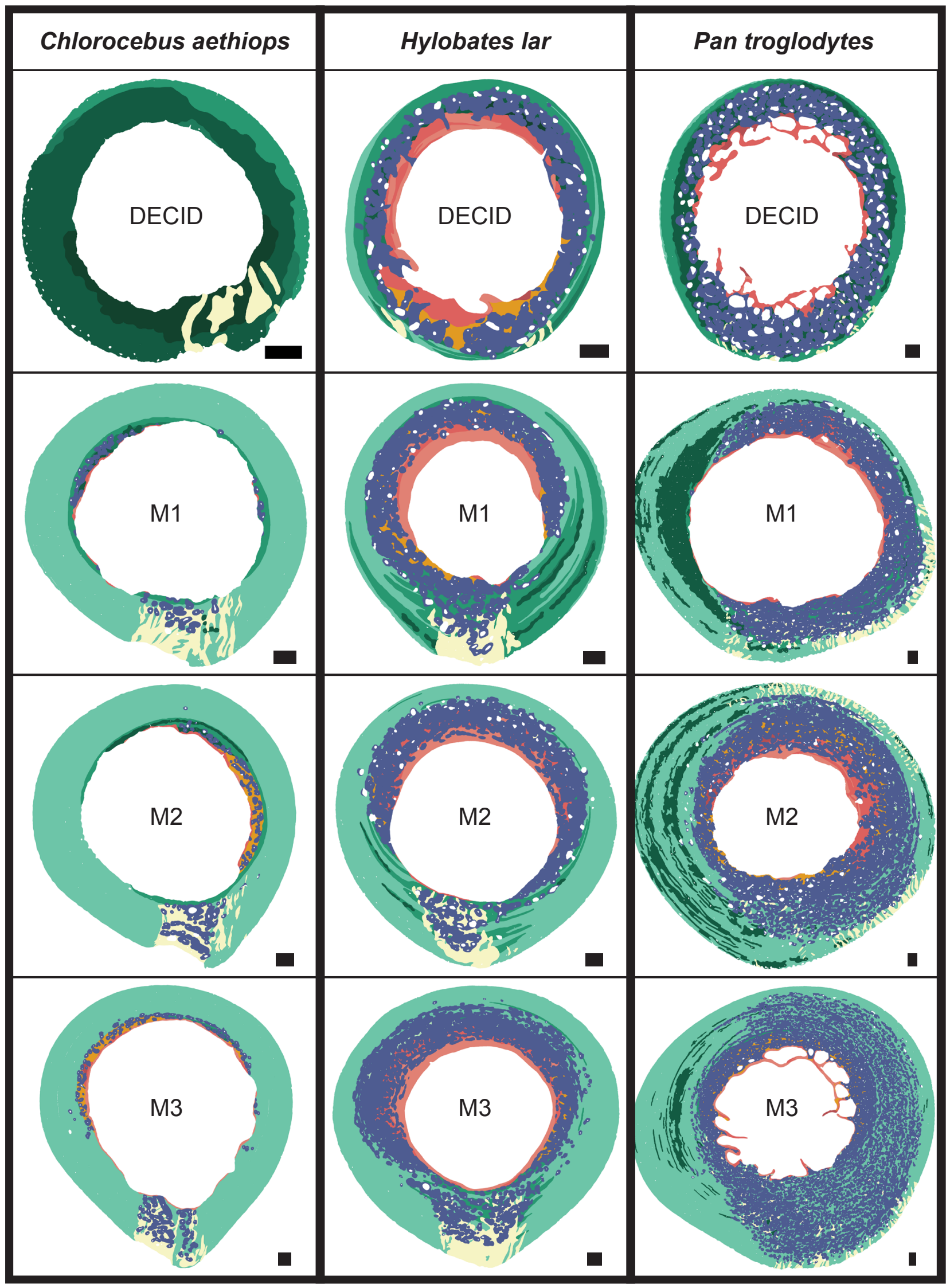


FIGURE 6

A. DECID age class.

(SLW 92)
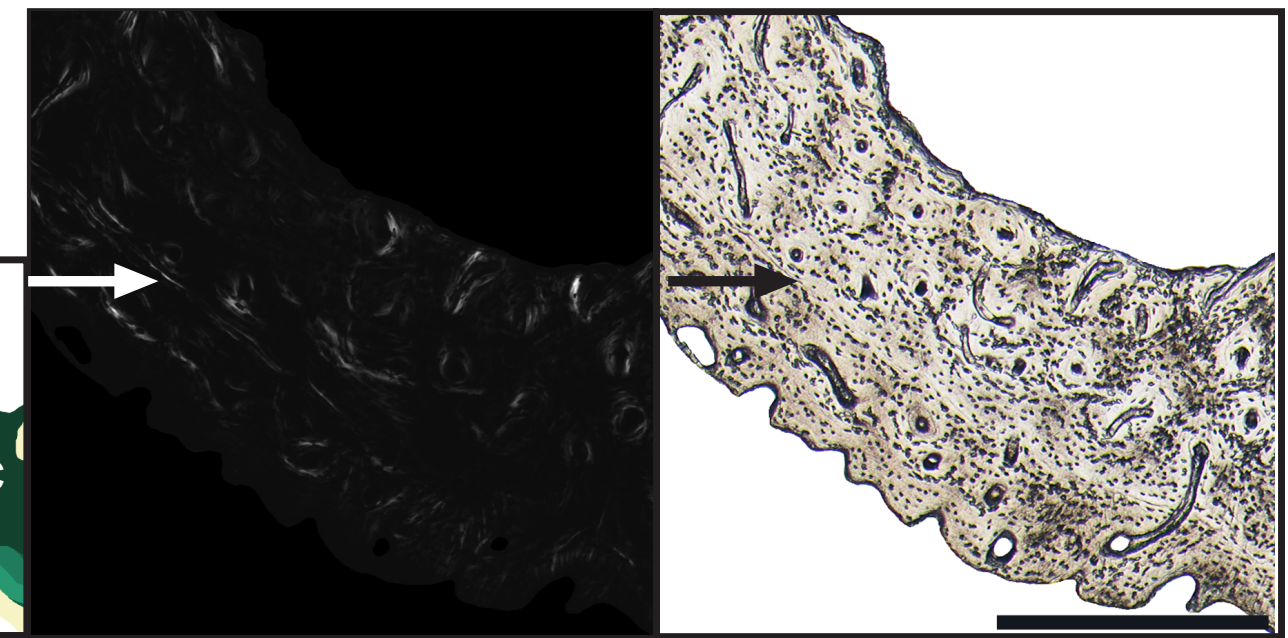

B. M1 age class.

(SLW 11)

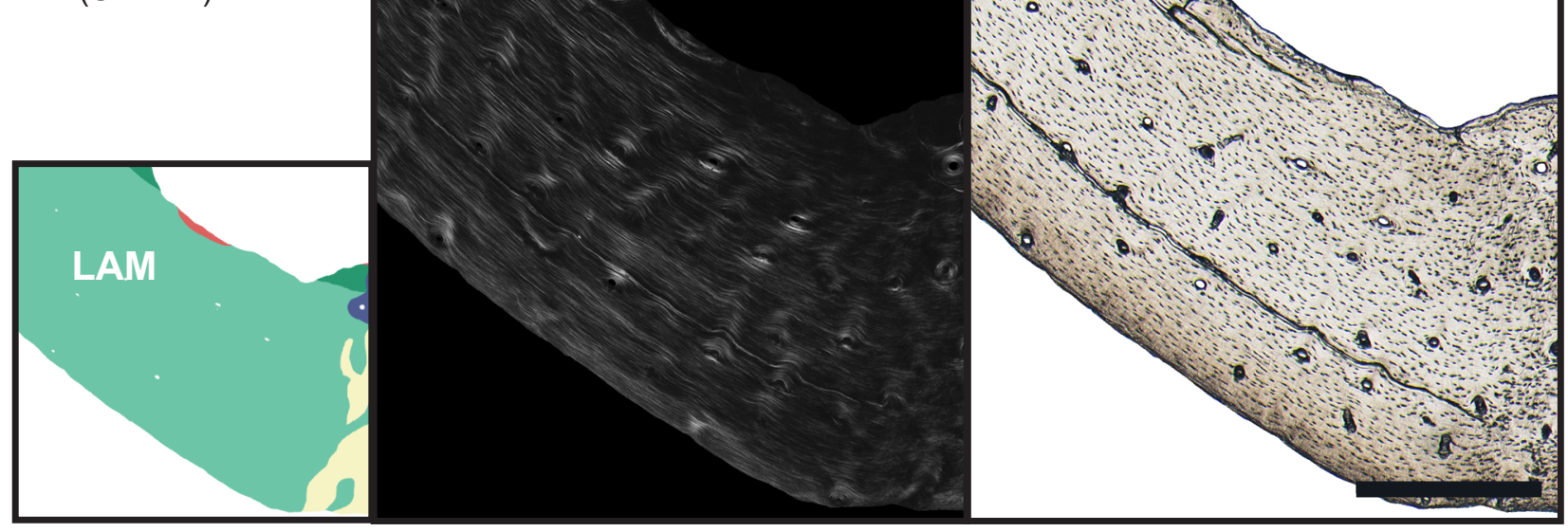

C. M2 age class. (SLW 34)
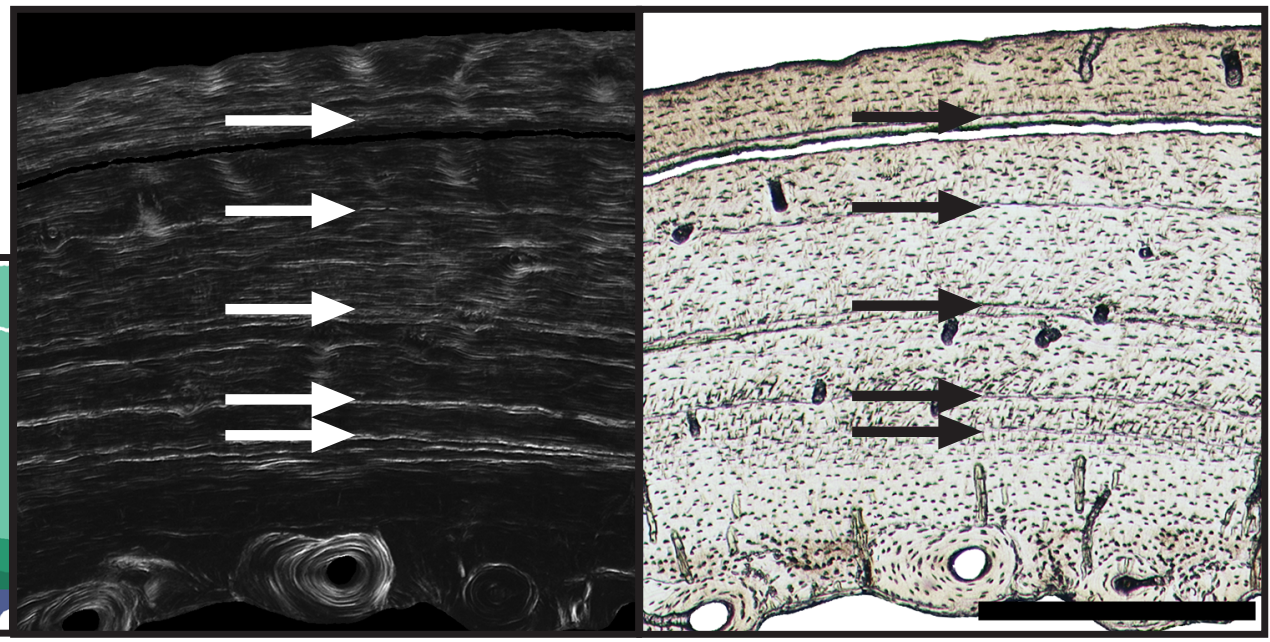
FIGURE 7

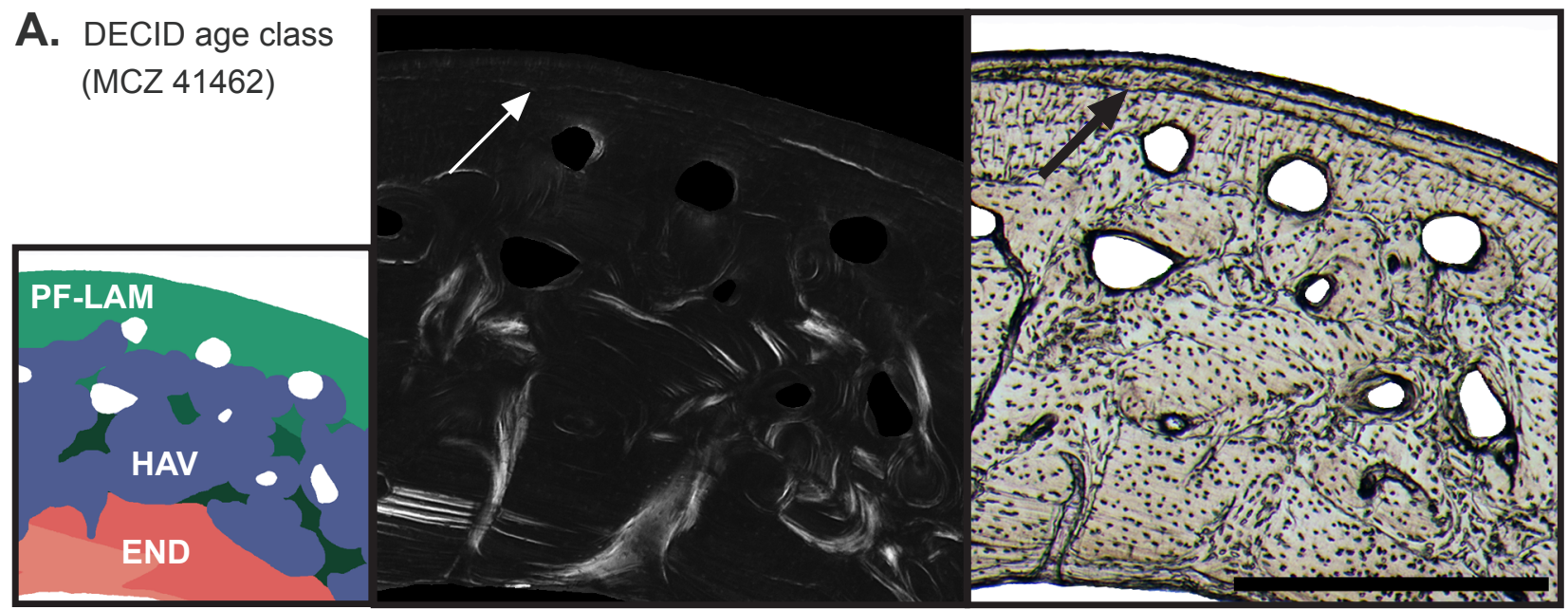

B. M1 age class (MCZ 41502)
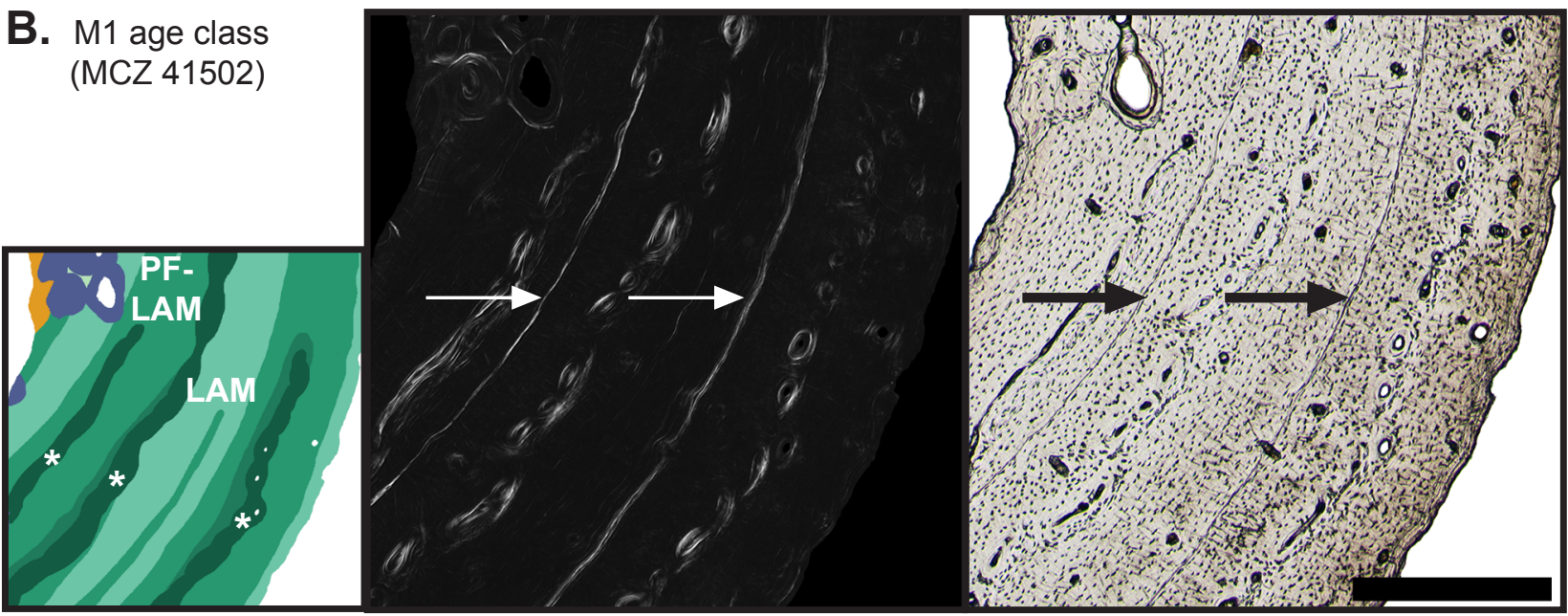

C. M3 age class. (SLW 37)
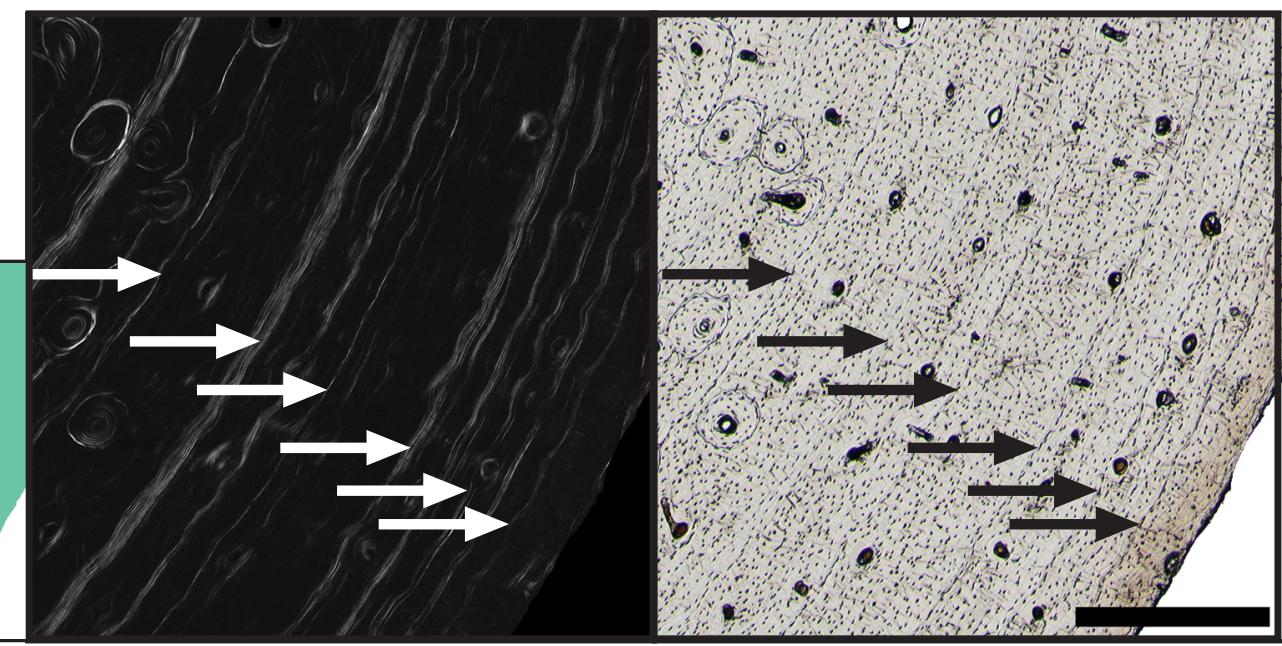
FIGURE 8

A. M1 age class

(MfN 83604)
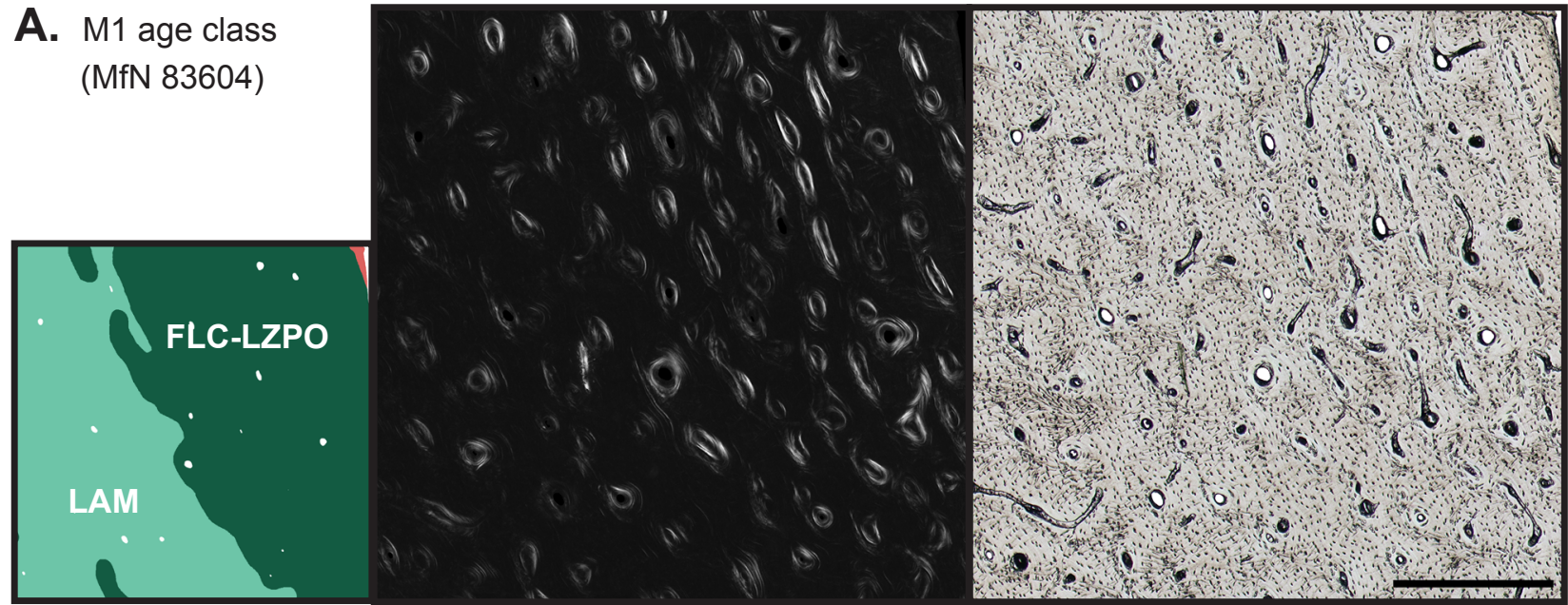

B. M2 age class

(MfN 32052)
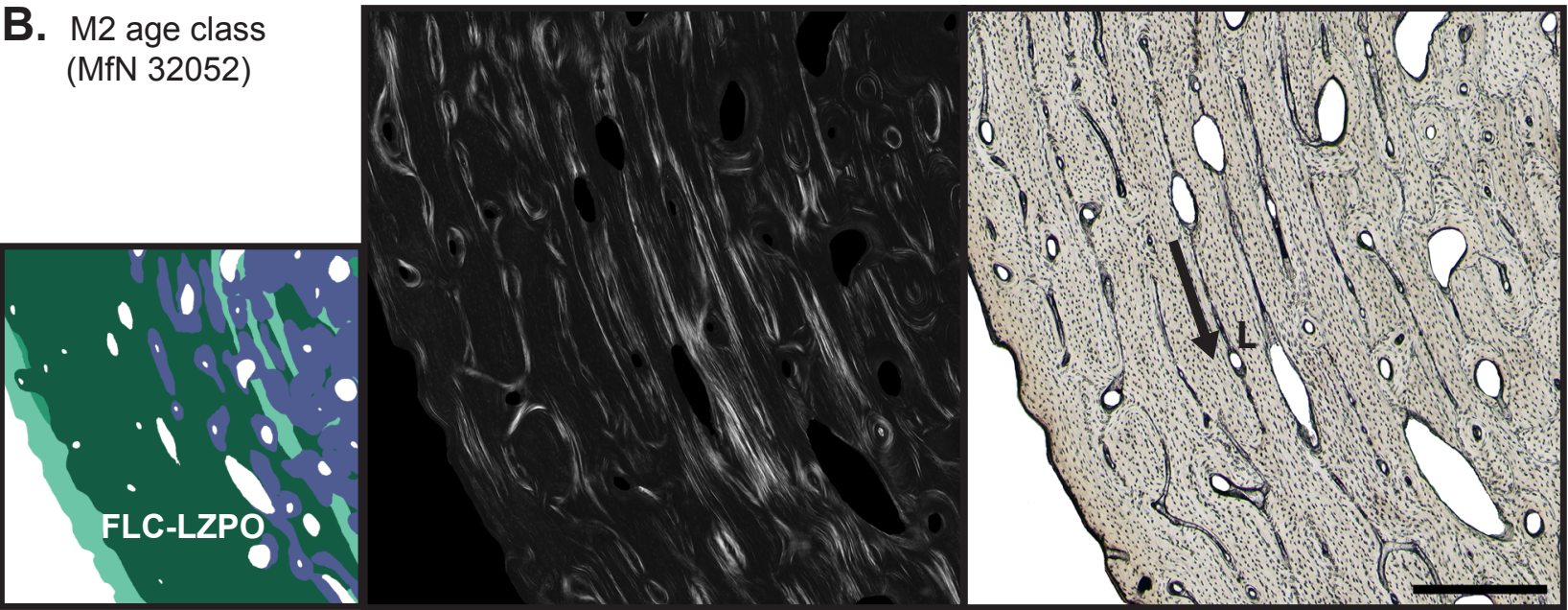

C. M2 age class. (MfN 83673)
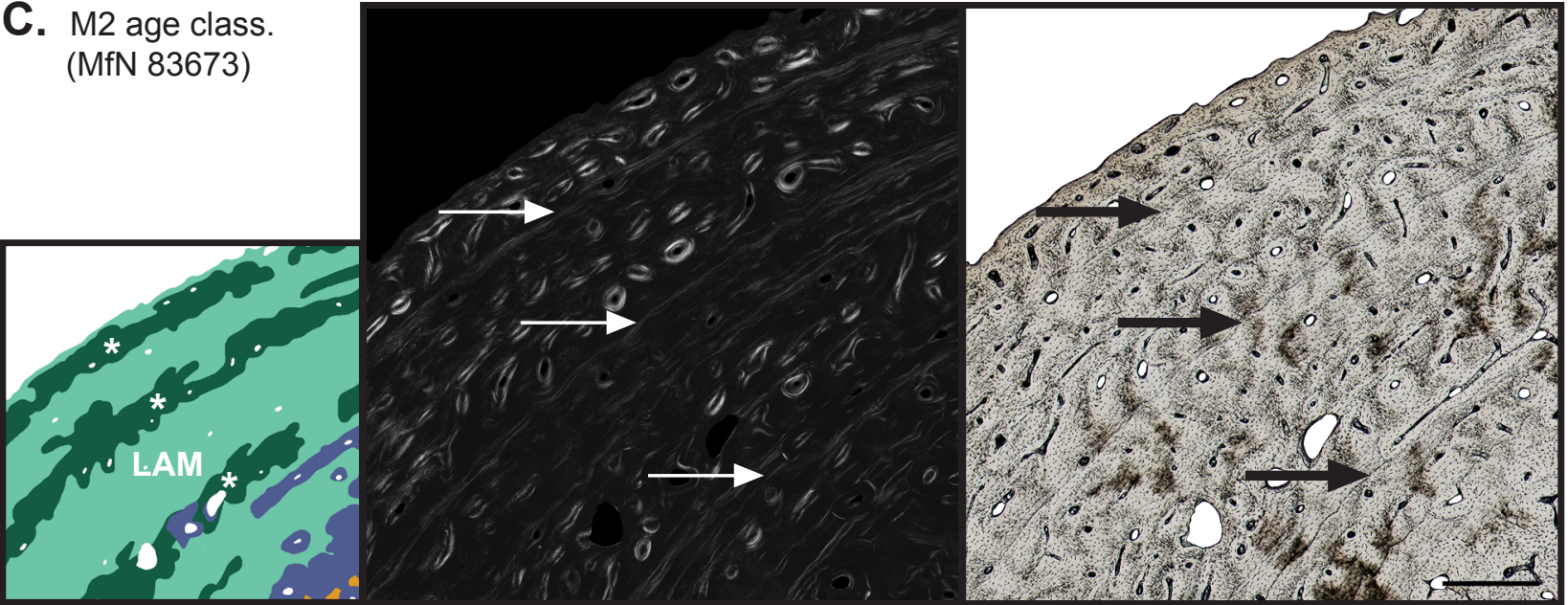
FIGURE 9
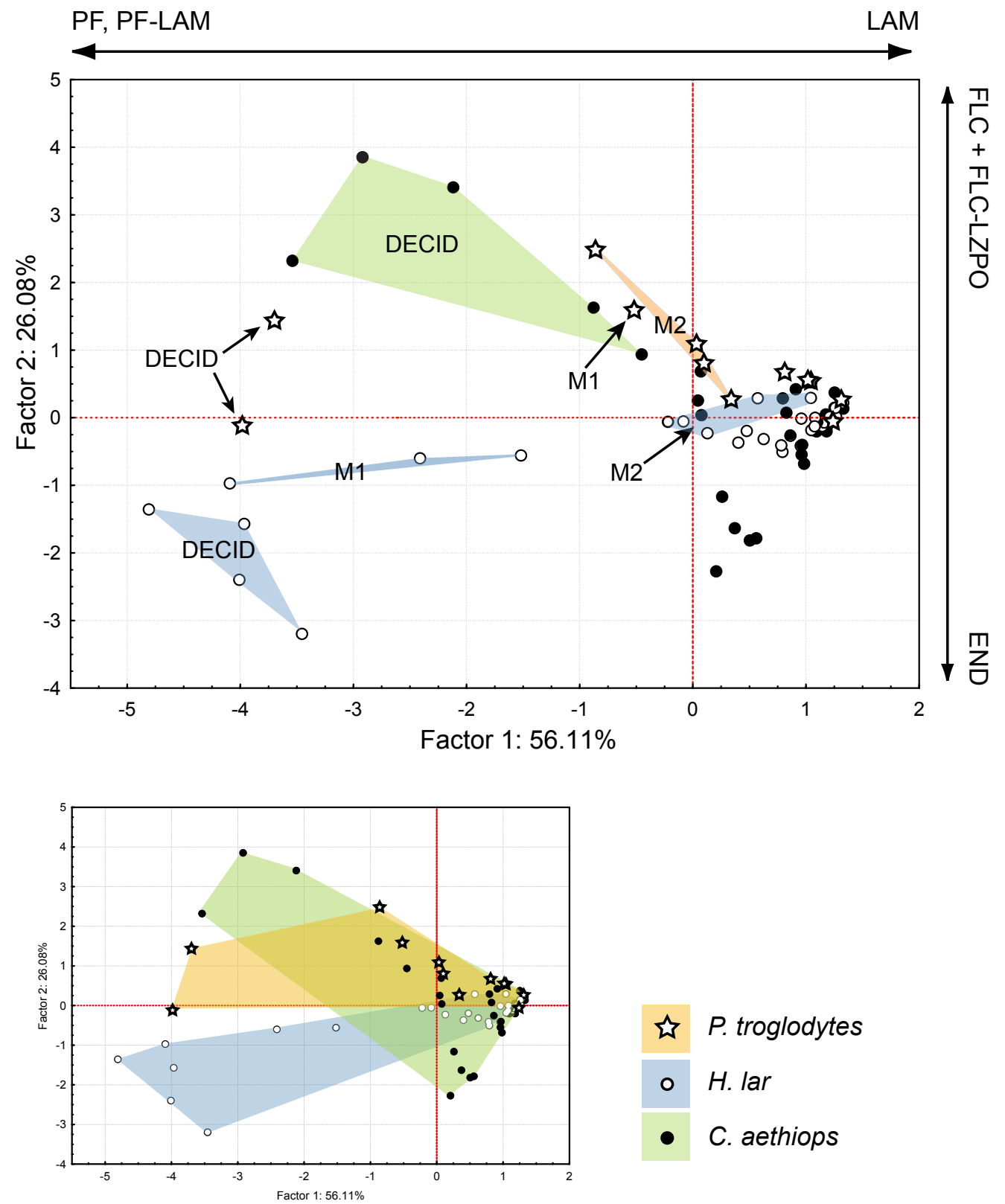
P. troglodytes
- H. lar
- C. aethiops 